\title{
Uncovering Olive Biodiversity through Analysis of Floral and Fruiting Biology and Assessment of Genetic Diversity of 120 Italian Cultivars with Minor or Marginal Diffusion
}

\author{
Luca Lombardo ${ }^{1,2, *} \mathbb{D}^{\circ}$, Gianni Fila ${ }^{3}{ }^{\oplus}$, Nicola Lombardo ${ }^{4}$, Chiara Epifani ${ }^{5}{ }^{\circledR}$, \\ Donald H. Duffy III 6,7, Gianluca Godino ${ }^{4}$, Amelia Salimonti ${ }^{4}$ (D) and Samanta Zelasco ${ }^{4}$ \\ Center Agriculture Food Environment (C3A), University of Trento, 38122 Trento, Italy \\ Research and Innovation Centre, Fondazione Edmund Mach, 38010 San Michele all'Adige, Italy \\ 3 CREA Research Centre for Agriculture and Environment, 40128 Bologna, Italy; gianni.fila@crea.gov.it \\ 4 CREA Research Centre for Olive, Citrus and Tree Fruit, 87036 Rende, Italy; nicolalombardo2@libero.it (N.L.); \\ gianluca.godino@crea.gov.it (G.G.); amelia.salimonti@crea.gov.it (A.S.); samanta.zelasco@crea.gov.it (S.Z.) \\ 5 CREA Research Centre for Agriculture and Environment, 00184 Roma, Italy; chiara.epifani@crea.gov.it \\ 6 Department of Computer Science and Automation Control, University of Salamanca, \\ 37007 Salamanca, Spain; dhduffy@usal.es \\ 7 Ketensis, New York, NY 10036, USA \\ * Correspondence: lombluca@yahoo.it
}

Received: 28 June 2019; Accepted: 26 August 2019; Published: 28 August 2019

\begin{abstract}
The primary impetus behind this research was to provide a boost to the characterization of the Italian olive biodiversity by acquiring reliable and homogeneous data over the course of an eight-year trial on the floral and fruiting biology of 120 molecularly analyzed cultivars, most of which have either low or very low diffusion. The obtained data highlighted a considerable variability to almost all of the analyzed parameters, which given the uniformity of environment and crop management was indicative of a large genetic variability in the accessions under observation, as confirmed through the molecular analysis. Several cases of synonymy were reported for the first time, even among plants cultivated in different regions, whilst all of the varieties examined, with only one exception, showed very low percentages of self-fruit-set, indicating a need for the employment of suitable pollinator plants. Eventually, a fitted model allowed us to evaluate the clear effects of the thermal values on blossoming, particularly in the months of March and April, whereas the climatic conditions during the flowering time had only a modest effect on its duration.
\end{abstract}

Keywords: Olea europaea L.; flowering; modelling; fruiting biology; SSR

\section{Introduction}

The olive tree (Olea europaea L.) usually blossoms rather abundantly, with up to half a million flowers per plant [1]. Nevertheless, the percentage of fruiting flowers is very low, generally below $2 \%$ [2-4]. This mainly comes down to genetic factors, such as pistil abortion and intraspecific self-incompatibility, which along with the summer fruit drop, biotic and abiotic stresses, and the presence of appropriate pollinators greatly influence the production potential of this andromonoecious species $[5,6]$. The study of floral and fruiting biology is therefore crucial from an agronomic and physiological point of view, especially considering the remarkable size of the olive germplasm, which is estimated to include 2629 accessions [7].

The scientific approach to the study of floral biology in olives traces its roots back to the first decade of the 20th century with the research conducted primarily by Petri [8] and Campbell [9], nevertheless, 
most of the available studies were carried out on a small number of cultivars, in vastly different environments, and over a limited number of years [10-21]. As a result, the conflicting reports regarding the classification of pollen compatibility in some cultivars, as well as the contradictory results in different areas and years [22], do not allow for definitive conclusions to be drawn. On the other hand, the few works on floral biology conducted in a comparative manner (in the same pedoclimatic conditions and cultivating techniques) $[5,23,24]$ looked at olive cultivars with medium or wide distribution, for which many data were already available. In this sense, the present work reports on data acquired for 120 varieties that have a mostly reduced or very low local distribution-in some cases being at risk of extinction $[25,26]$ - and which have been seldom studied, if at all. Since these data are utilized to describe, identify, and classify the cultivars, as recognized by the International Union for the Protection of New Varieties of Plants (UPOV) Guideline TG/99/4, the objective of this work is to provide a more thorough understanding of the vast Italian olive germplasm, which appears to be the richest in the world, comprising over 800 varieties [27]. Accordingly, the molecular characterization of these varieties will provide a further step forward towards the proper identification of the olive genotypes, while the knowledge of population structure and genetic variability of the olive germplasm is essential to define priorities for management and conservation of gene pools and to study the impact of domestication on olive tree genetic variability [28]. Eventually, a phenological model fitted to the reported flowering dates allowed us to characterize the cultivar-dependent variation of flowering time.

\section{Materials and Methods}

The research was conducted within the varietal collection field of the national olive germplasm located in Mirto, on the Ionian coast of the province of Cosenza, Italy (Figure 1). The classic collection method was applied to the staging of the field: land surveying, identification of varieties and ecotypes, foundational customization, and introduction into the collection field. Moreover, materials identified by Italian scientific institutions were introduced. To date, about 500 varieties and clones have been introduced to the collection (four to five plants for each accession).

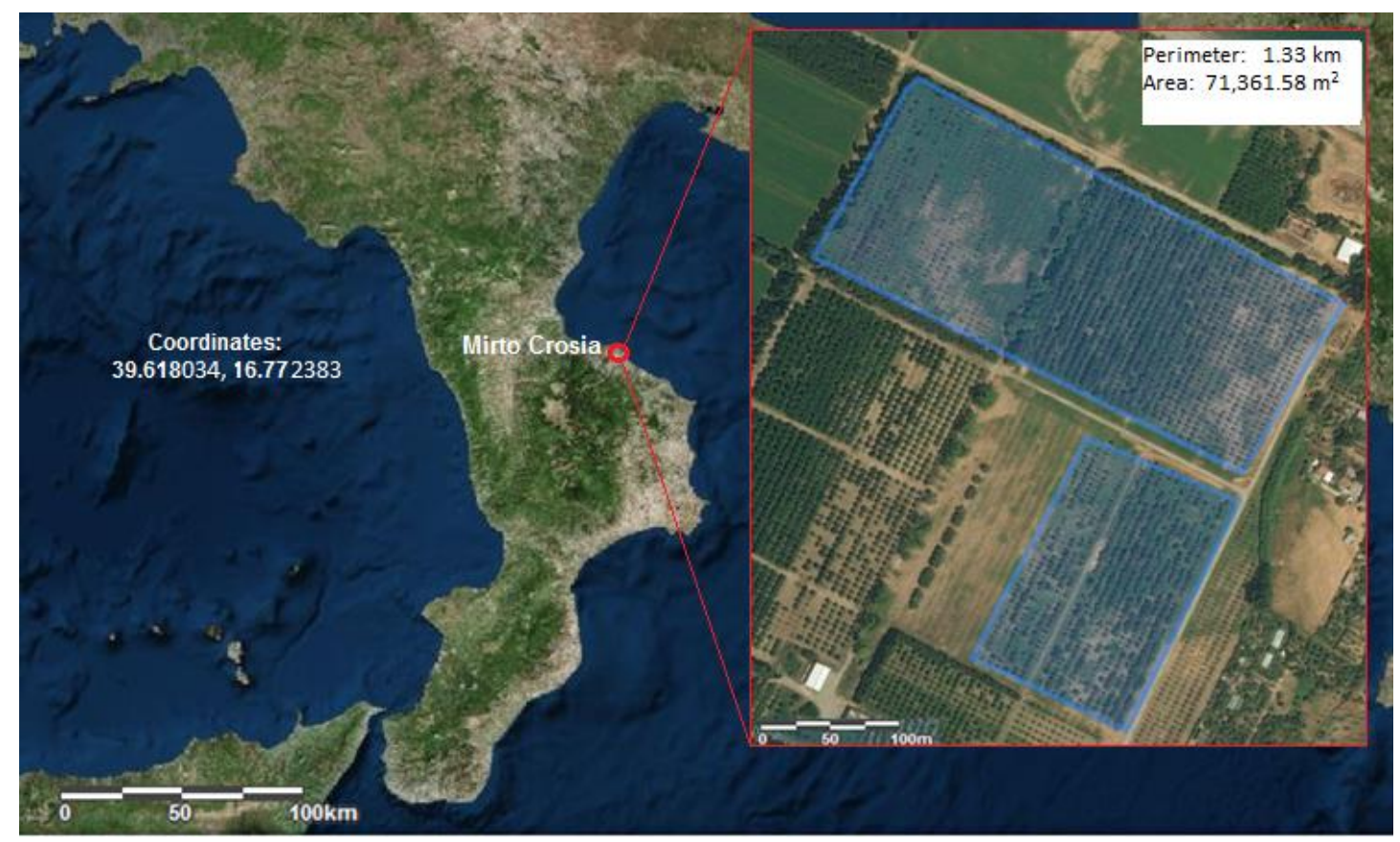

Figure 1. Geographical coordinates of the olive germplasm collection field.

The climate is semi-arid, with an average annual temperature of $18.9^{\circ} \mathrm{C}$ and an average annual precipitation of about $500 \mathrm{~mm}$, with modest year-to-year variations, which is sufficient so as to have had notable effects on some processes (the start of the blossoming, for example). Lack of precipitation, 
especially in summertime, was offset by a subsurface drip irrigation system. The field is maintained in accordance with sustainable management, with a vegetation cover (mowed in summertime), occasional fertilization using ternary fertilizers, and light annual pruning. The meteorological data (minimum, maximum, and average temperature, relative humidity, and precipitation amounts) for the phenological model were collected in situ by means of a meteorological station. The meteorological trend over the eight years of study is reported in Figure 2.

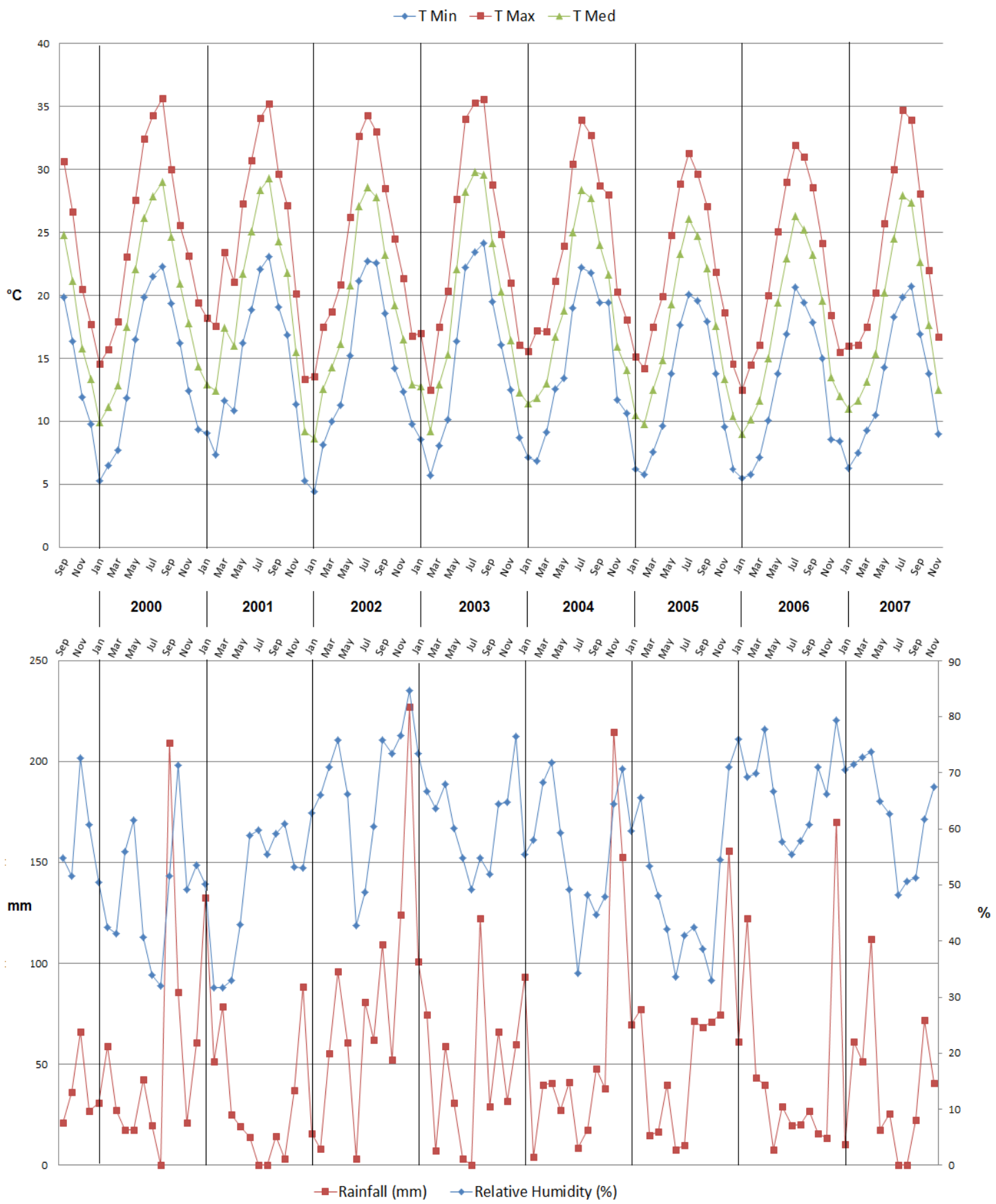

Figure 2. Climatic conditions during the eight-year trial.

Measurements for each parameter were performed on five plants (four plants for rare cases of plants that are either heavily diseased or explanted) for each of the 120 cultivars selected, and were repeated for eight consecutive years, from 2000 to 2007, in order to account for any anomalous values in production and the influence of climatic conditions. The parameters considered are reported below. 


\subsection{Phenological and Physiological Characteristics}

\subsubsection{Amount of Flowering}

Visual observations were carefully conducted during the flowering phase (March and April) throughout the eight consecutive years through randomized comparisons of the differentiation percentages of the flower buds of a similar number of the plants' tagged twigs. Specifically, every year at the time of inflorescence formation, an adequate number of twigs were tagged on the plants for a total of over 3000 inflorescences per variety. Meanwhile, an adequate number of twigs in blossom bearing an equivalent number of inflorescences were bagged in such a way as to enable the assessment of the fruit set from self-pollination.

The plants were divided into four classes: those without inflorescences (or at most with an insignificant number of inflorescences), plants with a low blossom profile (1 to $30 \%$ flower differentiation), plants with intermediate flowering (30-60\% differentiation), and plants with an elevated blossom percentage (60-90\% or higher).

\subsubsection{Timing and Duration of Flowering}

The observations were carried out three times a week over the relevant period (April-June). The flower development stages were recorded according to the $\mathrm{BBCH}$ (Biologische Bundesanstalt, Bundessortenamt and CHemical industry)-scale [29]. In particular, the stages considered were: BBCH60: beginning of flowering - up to $10 \%$ of flowers open; $\mathrm{BBCH} 65$ : full flowering-at least $50 \%$ of flowers open; and $\mathrm{BBCH} 69$ : end of flowering-all petals have fallen. The data were utilized for an explorative analysis of the cultivar-dependent variability of flowering time, and to individuate date thresholds to discriminate cultivars amongst early, medium, and late flowering varieties.

\subsubsection{Length of the Inflorescences, Number of Flowers per Inflorescence, and Pistil Abortion}

In the stage prior to flower opening, a variable number of flowering buds (depending on the extent of the individual plant's blossom) were cut so as to have at least 200 blossoms per variety every year (which correspond to an average of over 3400 flowers for every variety) before being transported to the laboratory to tally the length of each inflorescence, the number of floral sprouts per inflorescence, as well as the pistil abortion percentage.

\subsubsection{Percentage of Fruit Set from Open and Self-Pollination}

Fifteen to 20 days after the blossom process had concluded (in June), the number of small fruits present on the tagged twigs as calculated along with the percentages of fruit set per inflorescence and per number of fertile flowers. At the same time, the bags were removed, and as mentioned above, the small fruits on the selected twigs were counted and compared with the total number of flowers and flowering buds. Eventually, the self-pollination index (SI) was calculated by taking the percentage of small fruits obtained through self-pollination and dividing it by the percentage of those obtained through open pollination. Values nearing 1 indicate a heightened degree of self-fertilization; values equaling or approaching 0 indicate a self-sterile variety.

\subsubsection{Fruit Drop}

The summer fruit drop was evaluated between July and September depending on the variety, observing the number of small fruits that remained on the tagged small branches during the first growth phase. 


\subsubsection{Drupe Weight}

The harvest of the drupes took place between October and December (depending on the variety) in order to have the olives at the same degree of veraison. Between 30 and 40 drupes per plant were weighed so as to have at least 150 values per variety each year.

\subsection{Model-Based Phenological Characterization}

Cultivar-dependent variation of flowering time was further characterized by means of a phenological model fitted to observational full flowering dates. In this way, the cultivar earliness classification was enriched with physiologically based information by providing quantitative estimates of the specific thermal requirements.

The model was chosen among a set of 11 candidate models of varying complexity, which are listed in Table S1 of the Supplementary Materials. All models were fitted to data and ranked according to the Akaike Information Criterion (AIC), which weighs the fit of a model with its complexity; when models of different complexity give similar results, the simplest model, i.e., the one with the lowest number of parameters, is preferred. The evaluation methodology is described in detail in the Supplementary Materials.

\subsection{Molecular Characterisation via SSR(simple sequence repeat) Analysis}

Sampled leaves were dried using silica gel ground to a fine powder and then stored at $-80{ }^{\circ} \mathrm{C}$ until the time of analysis. Total genomic DNA was extracted from leaves using a commercial kit (Plant DNA Mini Kit, Qiagen, Germany). The DNA quality was checked with a NanoDrop 2000 spectrophotometer (Thermo scientific, Waltham, MA, USA). A set of twelve labelled microsatellites (SSRs), most of them widely used in literature, were chosen based on their amplification consistency via polymerase chain reaction (PCR), polymorphism, and ease of allele scoring in both conventional and multiplex amplification strategies [30-35]: DCA3-6Fam, DCA5-VIC, DCA8-VIC, DCA9-6Fam, DCA11-PET, DCA16-VIC, DCA18-6Fam [36], GAPU71B-6Fam, [37], UDO12-NED, UDO15-NED [38], EMO090-6Fam [39], and OLEST23-PET [40] loci were used in this work. Different combinations of three SSR loci were used in a multiplex PCR amplification strategy, except for DCA9-6Fam and DCA16-VIC, which showed allele drop-out during multiplex amplification. Multiplexed PCRs were carried out in $15 \mu \mathrm{L}$ final volume using a thermal cycler (GeneAmp PCR System 9700 Applied Biosystems Inc., Foster City, CA, USA). The reaction mixture was composed of $10 \mathrm{ng}$ of template DNA, 10X PCR buffer, $2 \mathrm{mM} \mathrm{MgCl} 2,2.5 \mathrm{mM}$ dNTPs, $10 \mu \mathrm{M}$ of forward and reverse primers, and $5 \mathrm{U} / \mu \mathrm{l}$ Taq polymerase. The PCR thermal profile was programmed as follows: a first step at $94^{\circ} \mathrm{C}$ for $5 \mathrm{~min}, 30$ cycles at $94{ }^{\circ} \mathrm{C}$ for $30 \mathrm{~s}, 55^{\circ} \mathrm{C}$ for $30 \mathrm{~s}$, and $72{ }^{\circ} \mathrm{C}$ for $40 \mathrm{~s}$. The last step included $7 \mathrm{~min}$ of incubation at $72{ }^{\circ} \mathrm{C}$.

Two reference varieties (Leccino and Frantoio) were included in PCR amplification to check experimental conditions (data not shown). The GeneScan 500 LIZ (Life Technologies, Carlsbad, CA, USA) was used as internal standard, and amplification products were separated on an ABI PRISM Genetic Analyzer 3130xl (Applied Biosystems Inc., Foster City, CA, USA). The allelic assignment was performed using GeneMapper 3.7v software. Standardization of raw data was conducted in comparison to the authenticated molecular profiles of Leccino and Frantoio reference varieties in accordance with Ben Mohamed et al. [33].

\section{Molecular Data Analysis}

Genetic diversity was evaluated using a cluster analysis of the 120 SSR profiles scored. A similarity matrix using Dice's coefficient $[41,42]$ was first obtained and used to determine the cluster analysis based on the unweighted pair group method with arithmetic mean (UPGMA). A dendrogram and cophenetic correlations were obtained using PAST software v.2.12. The number of alleles detected per locus $(\mathrm{Na})$, the observed $(\mathrm{Ho})$ and expected $(\mathrm{He})$ heterozigosity, polymorphism information content 
(PIC), the number of null alleles (F null), and the deviation from the Hardy-Weinberg equilibrium (HW) corrected using the Bonferroni method were determined using Cervus v.3.0.7 [43-45].

The Wright's inbreeding coefficients, Fis, Fit, and Fst, and gene flow (Nm) estimates were calculated using PopGene 1.32 [46].

A population structure analysis was also conducted using STRUCTURE v. 2.3.4 software [47] to establish the Bayesian relationships amongst the 120 Italian varieties. The admixture model with correlated allele frequency and a burn-in length of 100,000 followed by 100,000 runs at each K with three iterations for every $K$ were used, with $K$ ranging from 1 to 12 . The true value of $K$ was determined using Structure Harvester web version 0.6.93 [48].

Eventually, a parentage analysis was computed using Cervus v.3.0.7 software. An approach based on the LOD (logarithm of the odds) score significance was adopted and the following parameters were run: (i) number of offspring: 100,000; (ii) number of candidate parents: 120; (iii) proportion of candidate parents sampled: 0.4 ; (iv) proportion of loci typed: 0.7208 . Default values were adopted for the parameters "proportion of loci mistyped" and "error rate in likelihood calculations". The relaxed and strict confidence levels were set to $95 \%$ and $99 \%$, respectively.

\section{Results}

\subsection{Phenological and Physiological Characteristics}

Table 1 shows the average values of the observed characters related to the floral biology of each of the 120 cultivars, along with the indication of the region of origin of the material used for the propagation or the alleged origin of the accession. The research results reveal that all of the examined features showed a wide range of variability. The most significant findings for the individual parameters are indicated below. 
Table 1. Characteristic of the examined parameters for the 120 olive varieties with the indication of their regions of origin.

\begin{tabular}{|c|c|c|c|c|c|c|c|c|c|c|c|c|c|c|c|}
\hline & \multirow[b]{3}{*}{ Cultivar } & \multirow[b]{3}{*}{ Region } & \multirow{2}{*}{\multicolumn{3}{|c|}{ Flowering }} & \multirow{3}{*}{$\begin{array}{c}\text { Length of the } \\
\text { Inflorescence } \\
\text { (mm) }\end{array}$} & \multirow{3}{*}{$\begin{array}{c}\begin{array}{c}\text { Flowers per } \\
\text { Inflorescence }\end{array} \\
\text { (n) }\end{array}$} & \multirow{3}{*}{\begin{tabular}{|c|}
$\begin{array}{c}\text { Pistil } \\
\text { Abortion }\end{array}$ \\
$(\%)$
\end{tabular}} & \multicolumn{4}{|c|}{ Fruit Set (\%) } & \multirow{3}{*}{$\begin{array}{c}\begin{array}{c}\text { Self-Pollination } \\
\text { Index }\end{array} \\
\text { (B/A) }\end{array}$} & \multirow{3}{*}{$\begin{array}{c}\begin{array}{c}\text { Fruit } \\
\text { Drop }\end{array} \\
(\%)\end{array}$} & \multirow{3}{*}{$\begin{array}{r}\begin{array}{r}\text { Drupe } \\
\text { Weigh }\end{array} \\
\text { (g) }\end{array}$} \\
\hline & & & & & & & & & \multicolumn{2}{|c|}{ Free Pollination (A) } & \multicolumn{2}{|c|}{ Self-Pollination (B) } & & & \\
\hline & & & Amount & Timing & Length & & & & $\begin{array}{c}\text { Fruits/ } \\
\text { Inflorescence }\end{array}$ & $\begin{array}{c}\text { Fruits/ } / \\
\text { Perfect } \\
\text { Flowers }\end{array}$ & $\begin{array}{c}\text { Fruits/ } \\
\text { Inflorescence }\end{array}$ & $\begin{array}{l}\text { Fruits/ } \\
\text { Perfect } \\
\text { Flowers }\end{array}$ & & & \\
\hline 1 & Abunara & Sicilia & high & medium & long & 26.19 & 16.31 & 15.6 & 28.48 & 2.07 & 7.88 & 0.57 & 0.28 & 44.47 & 6.26 \\
\hline 2 & Agristigna & Calabria & high & medium & long & 23.92 & 17.46 & 55.75 & 16.92 & 2.19 & 1.72 & 0.22 & 0.1 & 55.73 & 6.04 \\
\hline 3 & Aitana & Sicilia & high & medium & long & 30.19 & 17.05 & 21.55 & 21.26 & 1.59 & 0.28 & 0.02 & 0.01 & 63.48 & 3.30 \\
\hline 4 & Arnasca & Liguria & high & medium & medium & 22.01 & 19.76 & 12.62 & 103.34 & 5.99 & 4.04 & 0.23 & 0.04 & 27.17 & 2.57 \\
\hline 5 & Ascolana dura & Marche & high & late & medium & 28.71 & 14.72 & 68.7 & 22.77 & 4.94 & 0 & 0 & 0 & 48.42 & 4.44 \\
\hline 6 & Aurina & Molise & medium & late & short & 26.86 & 21.28 & 55.76 & 80.31 & 8.53 & 0.11 & 0.01 & 0 & 36.85 & 1.37 \\
\hline 7 & Biancolilla & Sicilia & high & medium & medium & 24.05 & 13.12 & 29.73 & 43.65 & 4.73 & 5.61 & 0.61 & 0.13 & 83.69 & 4.16 \\
\hline 8 & Borgiona & Umbria & medium & medium & medium & 37.40 & 15.14 & 35.66 & 30.33 & 3.11 & 4.48 & 0.46 & 0.15 & 38.42 & 3.67 \\
\hline 9 & Bottone di gallo & Sicilia & high & medium & medium & 30.86 & 20.11 & 66.19 & 43.02 & 6.33 & 0.54 & 0.08 & 0.01 & 25.27 & 2.00 \\
\hline 10 & Cacaredda & Sicilia & medium & early & long & 27.28 & 14.09 & 11.57 & 35.83 & 2.87 & 4.74 & 0.38 & 0.13 & 34.68 & 4.23 \\
\hline 11 & Caizzana & Campania & high & medium & medium & 31.09 & 16.65 & 20.52 & 34.97 & 2.64 & 0 & 0 & 0 & 28.13 & 2.24 \\
\hline 12 & Cammorotana & Campania & medium & medium & medium & 22.85 & 13.37 & 22.74 & 30.09 & 2.91 & 0.86 & 0.08 & 0.03 & 45.64 & 4.70 \\
\hline 13 & Capolga & Marche & high & medium & medium & 20.96 & 14.91 & 47.51 & 27.59 & 3.53 & 0.21 & 0.03 & 0.01 & 28.74 & 4.70 \\
\hline 14 & $\begin{array}{c}\text { Caprina di } \\
\text { Casalanguida }\end{array}$ & Abruzzo & medium & early & medium & 22.08 & 12.26 & 58.08 & 38.19 & 7.43 & 0.1 & 0.02 & 0 & 0.00 & 2.78 \\
\hline 15 & Caprina Vastese & Abruzzo & medium & late & short & 31.46 & 18.64 & 27.74 & 90.04 & 6.68 & 0.36 & 0.03 & 0 & 0.00 & 2.11 \\
\hline 16 & Carbonchia & Abruzzo & medium & medium & medium & 24.17 & 12.25 & 29.62 & 23.32 & 2.71 & 0.1 & 0.01 & 0 & 32.82 & 1.91 \\
\hline 17 & Carpellese & Campania & medium & medium & medium & 34.89 & 15.68 & 7.08 & 72.64 & 4.99 & 19.69 & 1.35 & 0.27 & 27.09 & 2.44 \\
\hline 18 & Carpinetana & Abruzzo & high & medium & short & 29.49 & 20.09 & 39.49 & 75.7 & 6.23 & 0.74 & 0.06 & 0.01 & 23.69 & 3.47 \\
\hline 19 & Castricianella & Sicilia & high & medium & medium & 29.49 & 21.32 & 50.05 & 28.18 & 2.65 & 0.67 & 0.06 & 0.02 & 23.56 & 2.05 \\
\hline 20 & Cavalieri & Sicilia & high & medium & medium & 27.24 & 18.04 & 41.85 & 32.18 & 3.07 & 0.26 & 0.03 & 0.01 & 29.88 & 2.90 \\
\hline 21 & Cellacchia & Lazio & high & late & medium & 26.06 & 20.68 & 69.06 & 19.69 & 3.08 & 7.29 & 1.14 & 0.37 & 11.44 & 2.47 \\
\hline 22 & Cellina di Rotello & Molise & medium & medium & medium & 37.64 & 18.49 & 12.94 & 69.58 & 4.32 & 30.65 & 1.9 & 0.44 & 32.10 & 3.07 \\
\hline 23 & Cicinella & Campania & high & medium & medium & 24.62 & 16.46 & 34.78 & 62.53 & 5.83 & 4.08 & 0.38 & 0.07 & 30.63 & 2.31 \\
\hline 24 & Colombina & Emilia & medium & medium & medium & 31.17 & 18.97 & 7.32 & 61.48 & 3.5 & 2.82 & 0.16 & 0.05 & 20.46 & 2.44 \\
\hline 25 & Corneglia & Campania & low & medium & medium & 31.15 & 16.31 & 17.64 & 24.38 & 1.81 & 2.67 & 0.2 & 0.11 & 9.84 & 3.39 \\
\hline 26 & Cornia & Campania & medium & medium & medium & 28.01 & 10.34 & 26.43 & 17.76 & 2.33 & 2.26 & 0.3 & 0.13 & 11.39 & 1.83 \\
\hline 27 & Corniola & Calabria & high & medium & medium & 25.20 & 18.24 & 52.51 & 35.6 & 4.11 & 0.74 & 0.09 & 0.02 & 26.25 & 3.24 \\
\hline 28 & Crognolo & Lazio & medium & medium & medium & 32.31 & 14.22 & 1.41 & 50.52 & 3.6 & 17.92 & 1.28 & 0.35 & 21.09 & 2.50 \\
\hline 29 & Dolce di Andria & Puglia & medium & early & long & 35.95 & 15.2 & 11.28 & 38.69 & 2.87 & 2.22 & 0.16 & 0.06 & 78.42 & 4.49 \\
\hline 30 & Dolce di Cerchiara & Calabria & medium & medium & medium & 27.78 & 15.11 & 66.25 & 19.81 & 3.88 & 0 & 0 & 0 & 45.25 & 3.43 \\
\hline 31 & Dritta di Loreto & Marche & high & medium & medium & 23.40 & 14.75 & 22.24 & $\begin{array}{l}77.42 \\
\end{array}$ & $\begin{array}{l}3.000 \\
6.75\end{array}$ & 0.77 & 0.07 & 0.01 & 32.11 & $\begin{array}{l}.45 \\
1.82\end{array}$ \\
\hline 32 & Erbano & Sicilia & high & late & medium & 25.72 & 17.66 & 42.53 & 42.07 & 4.14 & 3.16 & 0.31 & 0.08 & 39.45 & 1.85 \\
\hline 33 & Faresana & Basilicata & high & medium & medium & 44.13 & 21.79 & 53.46 & 25.37 & 2.5 & 0 & 0 & 0 & 36.47 & 4.56 \\
\hline 34 & Femminella di & Campania & medium & medium & medium & 30.60 & 19.72 & 35.76 & 43.11 & 3.4 & 2.43 & 0.19 & 0.06 & 33.95 & 1.97 \\
\hline 35 & Fosco & Lazio & medium & late & short & 38.61 & 24.59 & 35.67 & 50.24 & 3.18 & 6.93 & 0.44 & 0.14 & 29.49 & 2.25 \\
\hline 36 & Gentile dell'Aquila & Abruzzo & medium & medium & long & 24.56 & 16.35 & 57.27 & 35.41 & 5.07 & 2.14 & 0.31 & 0.06 & 44.59 & 4.50 \\
\hline 37 & Ghiannara & Basilicata & medium & medium & medium & 28.34 & 12.84 & 18.22 & 54.51 & 5.19 & 6.99 & 0.67 & 0.13 & 35.56 & 2.34 \\
\hline 38 & Giarfara & Sicilia & high & medium & long & 30.07 & 14.04 & 10.86 & 51.71 & 4.13 & 0.19 & 0.02 & 0 & 55.44 & 5.70 \\
\hline $\begin{array}{l}50 \\
39\end{array}$ & Giusta & Basilicata & medium & early & medium & 30.04 & $\begin{array}{l}14.04 \\
14.34\end{array}$ & $\begin{array}{l}10.00 \\
15.2\end{array}$ & 46.8 & $\begin{array}{l}4.15 \\
3.85\end{array}$ & 0.3 & 0.02 & 0.01 & 20.64 & 3.69 \\
\hline 40 & Gnagnaro & Molise & medium & late & short & 32.13 & 19.47 & 13.52 & 87.82 & 5.22 & 10.11 & 0.6 & 0.12 & 18.76 & 0.79 \\
\hline
\end{tabular}


Table 1. Cont

\begin{tabular}{|c|c|c|c|c|c|c|c|c|c|c|c|c|c|c|c|}
\hline & \multirow[b]{3}{*}{ Cultivar } & \multirow[b]{3}{*}{ Region } & \multirow{2}{*}{\multicolumn{3}{|c|}{ Flowering }} & \multirow{3}{*}{$\begin{array}{c}\begin{array}{c}\text { Length of the } \\
\text { Inflorescence }\end{array} \\
\text { (mm) }\end{array}$} & \multirow{3}{*}{$\begin{array}{c}\begin{array}{c}\text { Flowers per } \\
\text { Inflorescence }\end{array} \\
\text { (n) }\end{array}$} & \multirow{3}{*}{$\begin{array}{c}\begin{array}{c}\text { Pistil } \\
\text { Abbortion }\end{array} \\
(\%)\end{array}$} & \multicolumn{4}{|c|}{ Fruit Set (\%) } & \multirow{3}{*}{$\begin{array}{c}\begin{array}{c}\text { Self-Pollination } \\
\text { Index }\end{array} \\
\text { (B/A) }\end{array}$} & \multirow{3}{*}{$\begin{array}{c}\begin{array}{c}\text { Fruit } \\
\text { Drop }\end{array} \\
(\%)\end{array}$} & \multirow{3}{*}{$\begin{array}{r}\begin{array}{r}\text { Drupe } \\
\text { Weight }\end{array} \\
\text { (g) }\end{array}$} \\
\hline & & & & & & & & & \multicolumn{2}{|c|}{ Free Pollination (A) } & \multicolumn{2}{|c|}{ Self-Pollination (B) } & & & \\
\hline & & & Amount & Timing & Length & & & & $\begin{array}{l}\text { Fruits/ } \\
\text { Inflorescence }\end{array}$ & $\begin{array}{l}\text { Fruits/ } \\
\text { Perfect } \\
\text { Flowers }\end{array}$ & $\begin{array}{l}\text { Fruits/ } \\
\text { Inflorescence }\end{array}$ & $\begin{array}{l}\text { Fruits/ } \\
\text { Perfect } \\
\text { Flowers }\end{array}$ & & & \\
\hline 41 & Grappolo & Toscana & medium & late & medium & 29.45 & 17.73 & 33.8 & 115.48 & 9.84 & 0.3 & 0.03 & 0 & 31.07 & 2.53 \\
\hline 42 & Grossa di Venafro & Molise & medium & late & medium & 36.88 & 28.78 & 35.35 & 66.41 & 3.57 & 12.5 & 0.67 & 0.19 & 26.91 & 2.49 \\
\hline 43 & Grossale & Campania & medium & medium & medium & 28.74 & 18.22 & 45.32 & 26.99 & 2.71 & 1.53 & 0.15 & 0.06 & 22.58 & 3.13 \\
\hline 44 & $\mathrm{I} / 77$ & Umbria & high & medium & medium & 36.15 & 20.89 & 81.76 & 35.25 & 9.25 & 0 & 0 & 0 & 46.60 & 3.79 \\
\hline 45 & Lumiaru & Sicilia & medium & medium & medium & 30.74 & 18.22 & 32.75 & 17.95 & 1.47 & 3.24 & 0.26 & 0.18 & 34.20 & 5.20 \\
\hline 46 & Mafra & Calabria & high & medium & medium & 37.80 & 25.38 & 79.23 & 25.81 & 4.9 & 0.51 & 0.1 & 0.02 & 42.58 & 3.31 \\
\hline 47 & Monaca & Sicilia & high & medium & medium & 29.51 & 25.08 & 73.33 & 15.05 & 2.25 & 0.21 & 0.03 & 0.01 & 40.80 & 4.29 \\
\hline 48 & Morchiaio & Toscana & high & medium & medium & 27.22 & 18.14 & 24.35 & 31.52 & 2.3 & 0.38 & 0.03 & 0.01 & 21.79 & 4.27 \\
\hline 49 & Morcone & Toscana & high & medium & medium & 27.50 & 21.25 & 25.47 & 39.69 & 2.51 & 3.78 & 0.24 & 0.1 & 11.26 & 1.64 \\
\hline 50 & Morellona di Grecia & Puglia & medium & late & short & 30.96 & 18.8 & 29.04 & 88.26 & 6.62 & 0.18 & 0.01 & 0 & 32.48 & 3.13 \\
\hline 51 & $\begin{array}{l}\text { Nasitana a frutto } \\
\text { grosso }\end{array}$ & Sicilia & high & medium & medium & 28.38 & 15.99 & 21.13 & 14.75 & 1.17 & 0.8 & 0.06 & 0.05 & 22.74 & 4.20 \\
\hline 52 & Nebba & Sicilia & high & medium & medium & 31.22 & 15.79 & 26.1 & 23.63 & 2.02 & 1.43 & 0.12 & 0.06 & 62.03 & 5.03 \\
\hline 53 & Nebbia & Marche & medium & medium & medium & 28.54 & 16.68 & 7.15 & 99.7 & 6.44 & 5.18 & 0.33 & 0.05 & 10.14 & 2.39 \\
\hline 54 & Nebbio di Pescara & Abruzzo & medium & medium & medium & 40.30 & 20.69 & 68.95 & 42.73 & 6.65 & 0.18 & 0.03 & 0 & 19.05 & 2.46 \\
\hline 55 & Nera di Colletorto & Molise & medium & medium & medium & 31.25 & 13.08 & 32.93 & 50.89 & 5.8 & 0.05 & 0.01 & 0 & 18.17 & 3.15 \\
\hline 56 & Nerba & Sicilia & medium & medium & medium & 23.07 & 14.01 & 45.45 & 22.14 & 2.9 & 1.79 & 0.23 & 0.08 & 63.64 & 4.43 \\
\hline 57 & Ogliara & Campania & high & medium & medium & 29.82 & 16.43 & 9.13 & 58.95 & 3.95 & 0.07 & 0 & 0 & 37.22 & 2.44 \\
\hline 58 & Ogliastro grande & Campania & high & late & medium & 28.01 & 14.17 & 52.41 & 24.62 & 3.65 & 0.33 & 0.05 & 0.01 & 33.80 & 4.71 \\
\hline 59 & Oliva grossa & Emilia & high & medium & medium & 26.96 & 18.46 & 90.75 & 2.27 & 1.33 & 0 & 0 & 0 & 45.53 & 6.97 \\
\hline 60 & $\begin{array}{l}\text { Olivastro di } \\
\text { Bucchianico }\end{array}$ & Abruzzo & medium & medium & medium & 35.49 & 18.63 & 65.79 & 19.66 & 3.08 & 7.8 & 1.22 & 0.4 & 30.62 & 2.46 \\
\hline 61 & Olivastro frentano & Abruzzo & high & late & short & 34.00 & 18.48 & 82.84 & 50.45 & 15.91 & 0.28 & 0.09 & 0.01 & 18.90 & 1.86 \\
\hline 62 & Olivella appuntita & Campania & high & late & short & 24.83 & 18.03 & 38.17 & 69.14 & 6.2 & 1.93 & 0.17 & 0.03 & 33.10 & 3.19 \\
\hline 63 & Olivella di Cerchiara & Calabria & high & medium & medium & 29.26 & 20.71 & 84.07 & 25.28 & 7.66 & 0.43 & 0.13 & 0.02 & 31.28 & 3.45 \\
\hline 64 & Olivo da mensa & Basilicata & high & medium & medium & 31.34 & 17.58 & 67.85 & 13.86 & 2.45 & 0.09 & 0.02 & 0.01 & 34.73 & 4.60 \\
\hline 65 & Olivo da olio & Campania & high & medium & medium & 28.58 & 14.91 & 12.74 & 58.94 & 4.53 & 0.23 & 0.02 & 0 & 22.18 & 2.42 \\
\hline 66 & Olivo da salare & Campania & medium & medium & long & 26.94 & 13.12 & 26.37 & 30.28 & 3.13 & 0.93 & 0.1 & 0.03 & 63.70 & 3.17 \\
\hline 67 & Olivo di Casavecchia & Toscana & medium & medium & medium & 30.48 & 13.8 & 16.85 & 22.08 & 1.92 & 0.4 & 0.03 & 0.02 & 22.90 & 3.06 \\
\hline 68 & Olivo di Castiglione & Sicilia & high & medium & medium & 20.00 & 10.56 & 9.7 & 18.21 & 1.91 & 0.82 & 0.09 & 0.05 & 59.00 & 4.51 \\
\hline 69 & Olivone di Viterbo & Lazio & high & medium & medium & 40.01 & 28.16 & 88.93 & 37.18 & 11.93 & 7.76 & 2.49 & 0.21 & 28.00 & 3.23 \\
\hline 70 & $\begin{array}{l}\text { Ornellaia } \\
\text { O }\end{array}$ & Toscana & high & medium & medium & 36.46 & 13.77 & 30.72 & 41.92 & 4.39 & 4.7 & 0.49 & 0.11 & 29.81 & 4.16 \\
\hline 71 & Ortice & Campania & medium & medium & medium & 34.54 & 22.84 & 58.17 & 45.27 & 4.74 & 0.15 & 0.02 & 0 & 25.89 & 2.54 \\
\hline 72 & Paesana bianca & Molise & medium & medium & medium & 35.29 & 16.92 & 10.69 & 35.38 & 2.34 & 9.79 & 0.65 & 0.28 & 51.40 & 2.45 \\
\hline 73 & Paesana nera & Molise & high & late & short & 34.26 & 23.18 & 29.86 & 69.38 & 4.27 & 2.88 & 0.18 & 0.04 & 43.37 & 2.49 \\
\hline 74 & Palmarola & Basilicata & medium & late & medium & 26.37 & 12.7 & 2.6 & 62.67 & 5.07 & 3.54 & 0.29 & 0.06 & 61.79 & 2.35 \\
\hline 75 & Passulunara & Sicilia & medium & medium & medium & 31.98 & 11.87 & 8.55 & 43.4 & 4 & 14.1 & 1.3 & 0.32 & 50.05 & 4.87 \\
\hline 76 & Pennulara & Calabria & medium & medium & medium & 24.29 & 10.64 & 13.22 & 21.62 & 2.34 & 21.94 & 2.38 & 1.01 & 62.05 & 4.61 \\
\hline 77 & Perciasacchi & Campania & high & medium & medium & 27.02 & 20.97 & 76.06 & 29.69 & 5.91 & 0.9 & 0.18 & 0.03 & 40.66 & 3.04 \\
\hline 78 & Pesciatino & Toscana & medium & medium & medium & 25.08 & 22.45 & 76.06 & 89.58 & 16.67 & 1.09 & 0.2 & 0.01 & 17.00 & 2.26 \\
\hline 79 & Piangente & Toscana & high & medium & long & 32.65 & 17.74 & 4.85 & 67.01 & 3.97 & 0.77 & 0.05 & 0.01 & 28.74 & 2.58 \\
\hline 80 & Pizzutella & Sicilia & high & medium & medium & 21.19 & 24.41 & 68.1 & 8.1 & 1.04 & 0.11 & 0.01 & 0.01 & 19.74 & 3.56 \\
\hline
\end{tabular}


Table 1. Cont

\begin{tabular}{|c|c|c|c|c|c|c|c|c|c|c|c|c|c|c|c|}
\hline & \multirow[b]{3}{*}{ Cultivar } & \multirow[b]{3}{*}{ Region } & \multirow{2}{*}{\multicolumn{3}{|c|}{ Flowering }} & \multirow{3}{*}{$\begin{array}{c}\text { Length of the } \\
\text { Inflorescence } \\
\text { (mm) }\end{array}$} & \multirow{3}{*}{$\begin{array}{c}\begin{array}{c}\text { Flowers per } \\
\text { Inflorescence }\end{array} \\
\text { (n) }\end{array}$} & \multirow{3}{*}{$\begin{array}{c}\begin{array}{c}\text { Pistil } \\
\text { Abortion }\end{array} \\
(\%)\end{array}$} & \multicolumn{4}{|c|}{ Fruit Set $(\%)$} & \multirow[b]{2}{*}{$\begin{array}{l}\text { Self-Pollination } \\
\text { Index }\end{array}$} & \multirow{3}{*}{$\begin{array}{r}\begin{array}{r}\text { Fruit } \\
\text { Drop }\end{array} \\
(\%)\end{array}$} & \multirow{3}{*}{$\begin{array}{r}\begin{array}{r}\text { Drupe } \\
\text { Weight }\end{array} \\
\text { (g) }\end{array}$} \\
\hline & & & & & & & & & \multicolumn{2}{|c|}{ Free Pollination (A) } & \multicolumn{2}{|c|}{ Self-Pollination (B) } & & & \\
\hline & & & Amount & Timing & Length & & & & $\begin{array}{l}\text { Fruits/ } \\
\text { Inflorescence }\end{array}$ & $\begin{array}{l}\text { Fruits/ } \\
\text { Perfect } \\
\text { Flowers }\end{array}$ & $\begin{array}{c}\text { Fruits/ } \\
\text { Inflorescence }\end{array}$ & $\begin{array}{l}\text { Fruits/ } \\
\text { Perfect } \\
\text { Flowers }\end{array}$ & $(\mathrm{B} / \mathrm{A})$ & & \\
\hline 81 & Posola & Abruzzo & medium & late & medium & 22.53 & 15.51 & 35.52 & 27.73 & 2.77 & 0.22 & 0.02 & 0.01 & 37.36 & 3.81 \\
\hline 82 & Posolella & Abruzzo & medium & medium & medium & 35.28 & 18.79 & 36.4 & 48.01 & 4.02 & 0.7 & 0.06 & 0.01 & 21.02 & 1.91 \\
\hline 83 & Procanica & Lazio & medium & medium & short & 35.06 & 15.87 & 1.07 & 90.44 & 5.76 & 2.49 & 0.16 & 0.03 & 34.41 & 2.54 \\
\hline 84 & Provenzale & Campania & high & early & long & 26.02 & 13.59 & 49 & 22.31 & 3.22 & 4.68 & 0.68 & 0.21 & 9.01 & 3.09 \\
\hline 85 & Puntella & Abruzzo & medium & late & medium & 31.34 & 21 & 71.55 & 49.57 & 8.3 & 3.91 & 0.65 & 0.08 & 23.07 & 2.05 \\
\hline 86 & Racioppa campana & Campania & high & late & medium & 31.06 & 21.38 & 13.57 & 47.46 & 2.57 & 0.71 & 0.04 & 0.01 & 26.02 & 3.50 \\
\hline 87 & Racioppa & Basilicata & medium & medium & medium & 24.82 & 19.58 & 31.21 & 107.62 & 7.99 & 0.55 & 0.04 & 0.01 & 24.10 & 2.41 \\
\hline 88 & Rajo & Umbria & high & medium & long & 37.06 & 15.43 & 28.32 & 62.91 & 5.69 & 1.49 & 0.14 & 0.02 & 13.92 & 2.48 \\
\hline 89 & Ravece & Campania & high & medium & medium & 25.68 & 14.76 & 51.74 & 36.88 & 5.18 & 1.19 & 0.17 & 0.03 & 36.15 & 2.99 \\
\hline 90 & Remugnana & Molise & medium & medium & medium & 32.59 & 18.28 & 2.26 & 81.07 & 4.54 & 0.96 & 0.05 & 0.01 & 26.87 & 1.96 \\
\hline 91 & Resciola di Venafro & Molise & medium & late & short & 35.36 & 19.99 & 44.47 & 49.36 & 4.45 & 6.84 & 0.62 & 0.14 & 20.29 & 2.55 \\
\hline 92 & Riminino & Lazio & high & early & medium & 46.65 & 28.59 & 76.56 & 39.32 & 5.87 & 2.82 & 0.42 & 0.07 & 53.71 & 3.82 \\
\hline 93 & Ritonnella & Campania & high & medium & long & 27.32 & 21.19 & 69.95 & 12.93 & 2.03 & 4.08 & 0.64 & 0.32 & 58.93 & 3.54 \\
\hline 94 & Rizzitella & Campania & medium & medium & short & 24.08 & 17.66 & 57.25 & 26.32 & 3.49 & 1.96 & 0.26 & 0.07 & 45.36 & 2.15 \\
\hline 95 & Rosciola coltodino & Lazio & high & early & medium & 36.49 & 24.04 & 61.69 & 82.01 & 8.9 & 1.13 & 0.12 & 0.01 & 28.01 & 1.85 \\
\hline 96 & Rosciola di Rotello & Molise & medium & medium & medium & 31.59 & 13.55 & 9.23 & 59.03 & 4.8 & 5.08 & 0.41 & 0.09 & 30.75 & 2.37 \\
\hline 97 & Rossina & Emilia & high & medium & medium & 21.23 & 14.18 & 30.1 & 62.99 & 6.36 & 3.34 & 0.34 & 0.05 & 38.93 & 1.52 \\
\hline 98 & Rotondella campana & Campania & high & medium & long & 27.50 & 15.52 & 45.38 & 49.71 & 5.87 & 2.88 & 0.34 & 0.06 & 52.27 & 3.31 \\
\hline 99 & Rotondella lucana & Basilicata & high & medium & medium & 28.20 & 12.25 & 30.41 & 23.47 & 2.75 & 6.63 & 0.78 & 0.28 & 12.27 & 2.91 \\
\hline 100 & Rustica & Abruzzo & high & medium & long & 27.71 & 15.41 & 66.52 & 27.65 & 5.36 & 0.46 & 0.09 & 0.02 & 29.46 & 3.88 \\
\hline 101 & Ruveia & Campania & high & medium & short & 21.21 & 19.11 & 55.66 & 52.89 & 6.24 & 0 & 0 & 0 & 16.76 & 2.23 \\
\hline 102 & Saligna & Molise & high & late & medium & 30.73 & 18.92 & 46.42 & 62.07 & 6.12 & 17.63 & 1.74 & 0.28 & 25.70 & 2.24 \\
\hline 103 & Sammartinara & Sicilia & medium & medium & medium & 30.23 & 14.16 & 34.31 & 56.66 & 6.09 & 0.34 & 0.04 & 0.01 & 31.19 & 3.76 \\
\hline 104 & Sammartinenga & Basilicata & high & early & long & 29.50 & 22.99 & 80.84 & 20.04 & 4.55 & 0 & 0 & 0 & 38.36 & 1.81 \\
\hline 105 & San Benedetto & Puglia & high & early & long & 28.64 & 15.65 & 10.18 & 28.69 & 2.04 & 0.09 & 0.01 & 0 & 23.91 & 3.93 \\
\hline 106 & Sanginara & Campania & high & medium & medium & 29.09 & 20.18 & 43.82 & 45.27 & 3.99 & 0.95 & 0.08 & 0.02 & 21.52 & 1.96 \\
\hline 107 & Santa Maria & Campania & medium & late & short & 37.47 & 15.58 & 39.11 & 73.69 & 7.77 & 2.81 & 0.3 & 0.04 & 17.85 & 1.91 \\
\hline 108 & Scarpetta & Basilicata & medium & late & medium & 29.29 & 15.98 & 27.91 & 86.06 & 7.47 & 0.43 & 0.04 & 0.01 & 21.75 & 2.11 \\
\hline 109 & Sessana & Campania & high & late & medium & 26.51 & 17.71 & 50.02 & 42.13 & 4.76 & 7.36 & 0.83 & 0.17 & 23.54 & 1.98 \\
\hline 110 & Sivigliana da olio & Sardegna & medium & medium & medium & 33.20 & 26.21 & 89.24 & 35.77 & 12.68 & 0 & 0 & 0 & 35.59 & 1.73 \\
\hline 111 & Spagnola di Missano & Liguria & high & medium & medium & 32.36 & 21.51 & 74.48 & 52.66 & 9.59 & 7.05 & 1.28 & 0.13 & 39.64 & 3.61 \\
\hline 112 & Spezzanese & Calabria & high & early & long & 24.86 & 13.95 & 19.28 & 29.48 & 2.62 & 14.46 & 1.28 & 0.49 & 30.31 & 5.70 \\
\hline 113 & Tenacella & Campania & high & late & short & 31.79 & 18.98 & 61.68 & 73.82 & 10.15 & 33.76 & 4.64 & 0.46 & 26.57 & 1.01 \\
\hline 114 & Tombarello & Calabria & high & medium & medium & 27.45 & 19.34 & 13.25 & 37 & 2.2 & 0.33 & 0.02 & 0.01 & 22.44 & 1.79 \\
\hline 115 & Tonda di Alife & Campania & high & late & medium & 31.16 & 22.13 & 42.77 & 57.91 & 4.57 & 8 & 0.63 & 0.14 & 31.09 & 2.70 \\
\hline 116 & Tonda dolce & Calabria & medium & early & medium & 25.84 & 14.26 & 25.45 & 27.74 & 2.61 & 0.17 & 0.02 & 0.01 & 43.28 & 2.89 \\
\hline 117 & Tunnulidda & Sicilia & medium & early & long & 27.18 & 15.73 & 14.9 & 37.97 & 2.84 & 5.31 & 0.4 & 0.14 & 37.60 & 4.13 \\
\hline 118 & Vigna della corte & Campania & medium & medium & medium & 21.25 & 12.71 & 30.97 & 14.32 & 1.63 & 1.12 & 0.13 & 0.08 & 0.00 & 2.72 \\
\hline 119 & Vocio & Umbria & medium & medium & medium & 25.51 & 15.17 & 36.32 & 23.57 & 2.44 & 5.17 & 0.54 & 0.22 & 20.23 & 4.09 \\
\hline 120 & Zarbo & Sicilia & low & medium & medium & 29.59 & 13.41 & 29.4 & 64.8 & 6.85 & 1.51 & 0.16 & 0.02 & 33.81 & 5.66 \\
\hline
\end{tabular}




\subsubsection{Amount of Flowering}

The amount of flowering was high in more than half of accessions, with variable percentage of flower differentiation ranging from $60 \%$ to over $90 \%$ of buds. The highest and most constant values were in the cultivars of Aitana, Cavalieri, I77, Nasitana a frutto grosso, Ogliastro grande, Olivone di Viterbo, Ritonnella, San Benedetto, and Tombarello.

Fifty-five varieties showed a medium amount of bloom, whilst the flowering was low in only two varieties (Cornia and Zarbo), an indication of late entry into production.

\subsubsection{Timing of Flowering}

The duration of the interphase, i.e., the time needed to pass from the beginning to full flowering, is almost constant amongst the varieties and over the years, equaling 6-7 days (the average duration of the interphase is 6.2 days, with a very small variability).

The stable relationship amongst flowering phenophases indicates the presence of a mechanism regulating the development pacing, which was further analyzed through modeling analysis (see below).

A negative correlation (Pearson's $r=-0.84$ ) was observed between the timing of BBCH60 (as well as $\mathrm{BBCH} 65$ ) and the average temperature in March, namely during the phase of development of the flower buds. In confirmation of this, an even higher correlation was found between the accumulated growing degrees (growing degree-days -GDD-) for the month of March and BBCH60 ( $\mathrm{r}=-0.87$ ). Growing degree-days for the month of March have been calculated with the formula:

$$
G D D=\sum_{\text {March } 31^{s t}}^{\text {March }} 1^{\text {st }}\left[\frac{T_{\max }+T_{\min }}{2}\right]-T b
$$

where base temperature $(\mathrm{Tb})=8$. This threshold temperature was chosen on the grounds of previous literature, which indicate that for Southern Italy temperature values range between 6 and $9^{\circ} \mathrm{C}$ [49-51].

A polynomial equation can be proposed here as:

$$
y=0.37 x^{2}-99.34 x+6,717
$$

with $\mathrm{R}^{2}=0.81$, where $y$ is the beginning of flowering (number of the day in the year) and $x$ is the GGD for the month of March. A rather similar correlation (Pearson's $r=-0.75$ ) was observed between $\mathrm{BBCH} 60$ and rainfall in March. This may suggest that in the flowering-inducing hot period, given the same temperature, a greater amount of rainfall favors an earlier opening of the flowers as a likely effect of factors such as an increased absorption of nutrients from the roots.

Once it was established that the annual data were normally distributed, we established the lower and upper limits in order to divide the varieties into "early" (E), "medium" (M), and "late" (L) for each year. With this criterion, each variety is identified by a string-a series of eight combinations (one for each year) of characters E, M, and L. The threshold value was identified according to two parameters: (i) the probability $(\alpha)$ associated with the event was sufficiently low; (ii) each variety presented a maximum of two characters simultaneously $(\mathrm{M}+\mathrm{L}$ or $\mathrm{M}+\mathrm{E})$ during the eight years. In our case, the optimal probability value corresponded to $\alpha=9 \%$ and the fixed limits were:

$$
\lim _{\text {sup }}=m+1.28 * s \quad \text { and } \quad \lim _{\text {inf }}=m-1.28 * s
$$

where $m$ is the mean and $s$ is standard deviation. The Bernoulli distribution was further employed as a reasonable criterion for unambiguous classification of $\mathrm{M}+\mathrm{L}$ or $\mathrm{M}+\mathrm{E}$ varieties, where it provides the probability that an event having an a priori probability of occurring in a test may occur $\mathrm{x}$ times in $\mathrm{N}$ repeated tests by pure effect of the case. Based on these considerations, we could reasonably classify the following varieties. 
Early varieties: Abunara, Caprina di Casalanguida, Dolce di Andria, Giusta, Provenzale, Rosciola Coltodino, Riminino, Sammartinenga, San Benedetto, Spezzanese, Tonda dolce, and Paesana Bianca;

Late varieties: Ascolana dura, Aurina, Caprina Vastese, Carpellese, Erbano, Fosco, Gnagnaro, Grossa di Venafro, Morellona di Grecia, Palmarola, Resciola di Venafro, Saligna, and Santa Maria.

The flowering phenogram (Figure 3) highlights the significant differences found through the years as a result of the climatic trend. This trend has been further investigated through a fitted phenological model.

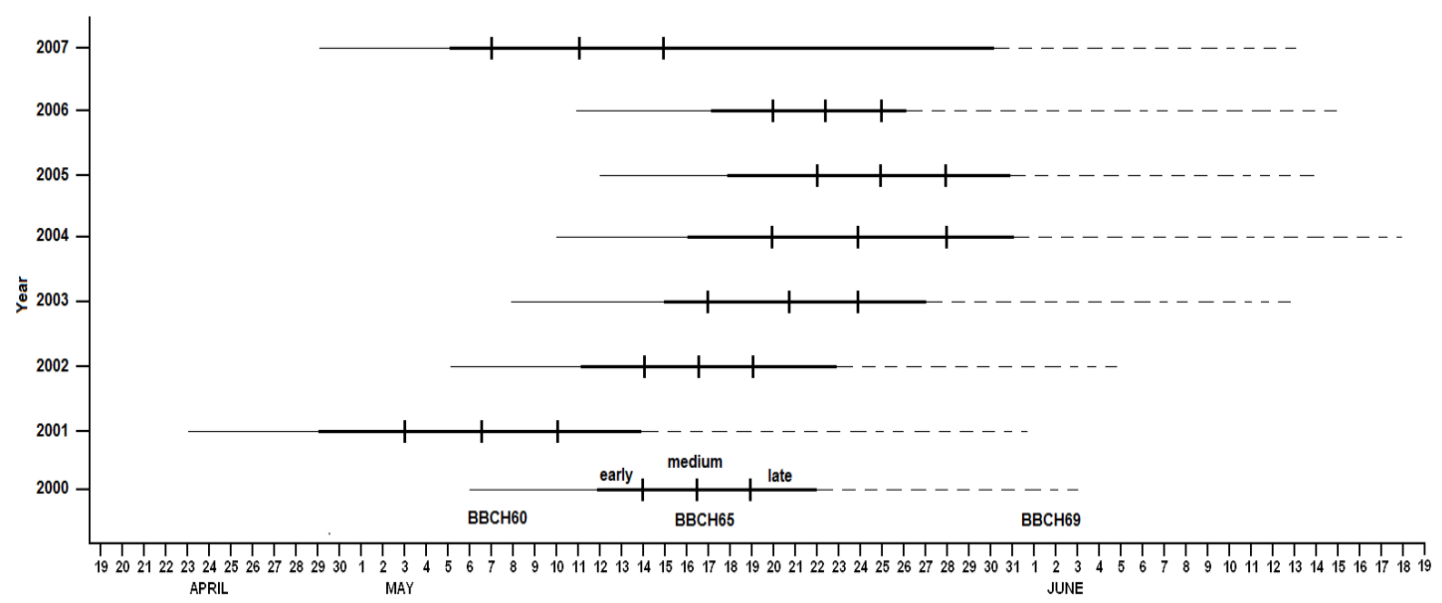

Figure 3. Phenogram illustration of flowering timing and duration over the eight years, with the indication of the limits calculated for early, medium, and late varieties.

\subsubsection{Duration of Flowering}

The same methodology used to set the optimal threshold for the identification of early and late flowering varieties was implemented to investigate the overall duration of flowering (BBCH60-BBCH69 interphase) and whether some olive varieties have intrinsic characteristics of "short flowering" or "long flowering". Again, a 9\% probability threshold allowed us to distinguish 15 varieties with a short duration of flowering, including Aurina, Gnagnaro, Morellona di Grecia, Procanica and Rizzitella. Eighteen cultivars had a longer flowering period, amongst them Abunara, Dolce di Andria, Gentile dell'Aquila, Rotondella campana, and Tunnulidda, while 87 showed medium flowering. The varieties of Resciola di Venafro Aurina, Caprina Vastese, Fosco, Gnagnaro, Morellona di Grecia, Resciola di Venafro, and Santa Maria presented both late and the short flowering features, whilst the varieties Dolce di Andria, Provenzale, Sammartinenga, San Benedetto, and Spezzanese had early and long flowering. In general, data analysis relating to timing and duration of flowering highlighted a certain trend towards long flowering for the cultivars with early anthesis and typically short ones for late-blooming varieties.

\subsubsection{Length of Inflorescences and Average Number of Flowers per Inflorescence}

The length of the inflorescences was on average $29.6 \mathrm{~mm}$, ranging from 20 (Olivo di Castiglione) to 46.65 (Riminino) $\mathrm{mm}$. Regarding the number of flowers per inflorescence, this parameter varied from 10.34 to 28.78 , with a general average being equal to $17.59 \pm 3.86$.

Amongst the varieties with small inflorescences were Cornia, Olivo di Castiglione and Pennulara; those with a higher number of flowers were Grossa di Venafro, Riminino and Olivone di Viterbo, all with an average of over 28 flowers.

\subsubsection{Pistil Abortion}

The percentage of pistil abortion for these 120 varieties turned out to have extreme variability, from $1 \%$ to $90 \%$, with a general average of $38.72 \%$. 
The varieties with a lower incidence of morphological sterility included Procanica $(1.07 \%)$, Crognolo (1.41\%), Remugnana $(2.26 \%)$, and Palmarola $(2.60 \%)$. Those with a higher percentage of abortion were Oliva grossa (90.75\%), Sivigliana da olio (89.24\%), and Olivone di Viterbo (88.93\%).

\subsubsection{Fruit Set by Open Pollination}

The fruit set by open pollination, expressed in fruits formed per hundred inflorescences, was extremely diversified, varying from $2.27 \%$ to $115.48 \%$, with a general average of $44.86 \%$.

The varieties with the highest productive potential — with percentages of fruit set over $100 \%$ were Grappolo (115.48\%), Racioppa della Basilicata (107.62\%), and Arnasca (103.34\%), followed by Nebbia, Procanica, and Caprina Vastese, with fruit sets over $90 \%$.

The varieties Oliva grossa, Pizzutella, Ritonnella, Oliva da mensa, Vigna della Corte, and Nasitana a frutto grosso showed the lowest fruit sets at below $15 \%$.

If fruit set is expressed in drupes formed per 100 fertile flowers, a parameter calculated to evaluate the combined incidence of the cytological and factorial forms of sterility, then the values obtained were obviously lower, and the variability reduced, ranging from 1.04 to $16.67 \%$.

The varieties with fruit set per fertile flower at over 10\% were Pesciatino, Olivastro Frentano, Sivigliana da olio, Olivone di Viterbo, Tenacella, and Grappolo; those with fruit set below $2 \%$ were Pizzutella, Nasitana a frutto grosso, Oliva grossa, Lumiaru, Aitana, Vigna della Corte, Olivo di Castiglione, and Oliva di Casavecchia.

\subsubsection{Fruit Set from Self-Pollination}

The percentage of self-fertility for the accessions considered in this study, intended as drupes formed per 100 bagged flowering buds, varied from 0 to 33.76 .

Nine varieties displayed a total self-incompatibility, namely Ascolana dura, Caiazzana, Dolce di Cerchiara, Faresana, I77, Oliva grossa, Ruveia, Sammartinenga, and Sivigliana da olio; only 10 varieties had a fruit set scope exceeding 10\%, and of these, only two surpassed 30\%,namely Cellina di Rotello and Tenacella.

These data clearly indicate that all 120 varieties are associated with an adequate number of suitable pollinator varieties.

Fruit set from self-pollination, expressed as fruits formed per 100 fertile bagged flowers, varied from 0 to 4.64; only 11 varieties surpassed $1 \%$, and the ones with higher values were Pennulara $(2.38 \%)$, Olivone di Viterbo (2.49\%), and Tenacella (4.64\%).

\subsubsection{Self-Pollination Index}

This index generally yielded very low results. Indeed, 22 varieties had a result equal or close to zero, 93 had a result below 0.4, and four were between 0.4 and 0.5 ; one exception is the Calabrian variety Pennulara, which registered a value of 1.01 , indicative of a self-fertility identical to open fertilization, and therefore not in need of pollinizers.

\subsubsection{Fruit Drop}

The summer fruit drop ranged between 0 (Caprina di Casalanguida, Caprina vastese, and Vigna della corte) and $83.69 \%$ (Biancolilla), with an average value of $32.43 \%$, confirming this phase as a crucial step for overall production.

\subsubsection{Drupe Weight}

This parameter varied from 0.79 (Gnagnaro) to over $6 \mathrm{~g}$ (Agristigna, Abunara, and Oliva grossa), with an average value of $3.13 \mathrm{~g}$. 


\subsection{Model Evaluation}

In terms of prediction accuracy, i.e., the capacity to predict the flowering date, all the models behaved better than the null model (Table S2 in the Supplementary Materials). The traditional GDD model, with an optimized base temperature of $2.25^{\circ} \mathrm{C}$ for all cultivars, was the best performing model, as it showed the lowest Akaike Information Criterion index (AIC) [52], which weighs the fit of a model versus its complexity. Variability among cultivars could therefore be characterized through only one parameter, corresponding to the cumulated GDD from January 1 until full flowering date.

The model was re-optimized using the whole 8-year dataset to obtain a final parameterization. The range of GDD sum, expressing the thermal requirements of the cultivars, was plotted in Figure 4, which shows the number of cultivars with specific exigencies, while the complete table with values for all cultivars is reported in Table S3 of the Supplementary Materials.

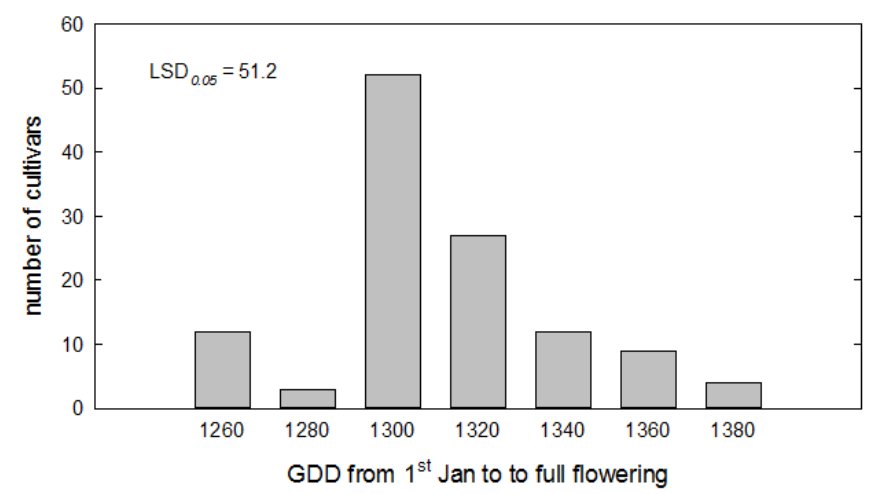

Figure 4. Distribution of cultivars according to the heat requirement to flower, expressed as growing degree days (Tbase $=2.25^{\circ} \mathrm{C}$ ) cumulated after January 1 up until full flowering.

The thermal requirement varies between 1251 and $1381{ }^{\circ} \mathrm{C} \mathrm{d}$.

Based on the optimized thermal time, the earliest cultivar (GDD sum $<1260$ ) were Tonda dolce, Rosciola coltodino, Giusta, Spezzanese, Dolce di Andria, San Benedetto, Sammartinenga, and Caprina di Casalanguida, while the latest ones (GDD sum > 1350) were Grappolo, Piangente, Grossa di Venafro, Saligna, Cellacchia, Santa Maria, Ascolana dura, Erbano, Racioppa, Fosco, Aurina, Gnagnaro, and Carpellese.

The thermal requirements to complete flowering (i.e., GDDs from beginning to end of flowering) were variable among the cultivars $(P<0.001)$, ranging between 188 and 316. Cultivars with the highest thermal requirements (GDDs $>300^{\circ} \mathrm{C} \mathrm{d}$ ) were Cacaredda, Rustica, and Tunnulidda, whereas those with the shortest requirements (GDDs $<195^{\circ} \mathrm{C}$ d) were Lumiaru, Santa Maria, Aurina, Caprina vastese, and Tenacella.

No significant correlation was found between the GDD required to complete flowering and those to begin flowering.

\subsection{SSR Diversity and Population Structure Analysis}

Molecular analysis conducted with a set of 12 microsatellites markers highlighted several cases of synonymy (Figure 5), although both the mean of the polymorphic information content (PIC $=0.73$ ) and the mean number of alleles per locus $(\mathrm{Na}=11.75)$ were relatively high $($ Table 2$)$. The mean expected heterozygosity (He) was 0.77 (ranging from 0.51 for OLEST23 to 0.9090 for DCA9), and the mean observed heterozygosity (Ho) was also 0.77 (ranging from 0.4 for OLEST23 to 0.97 for DCA8). In eight cases Ho was higher than He (DCA3, DCA5, DCA8, DCA18, GAPU71b, EMO090, DCA9, UDO12), indicating high genetic variability amongst the cultivars analyzed. The probability of null alleles ranged from -0.02 to 0.3 . Significant loss of heterozygosity was observed at the DCA16 and DCA11 loci; in this latter marker, the highest null allele value was found (Table 2). 


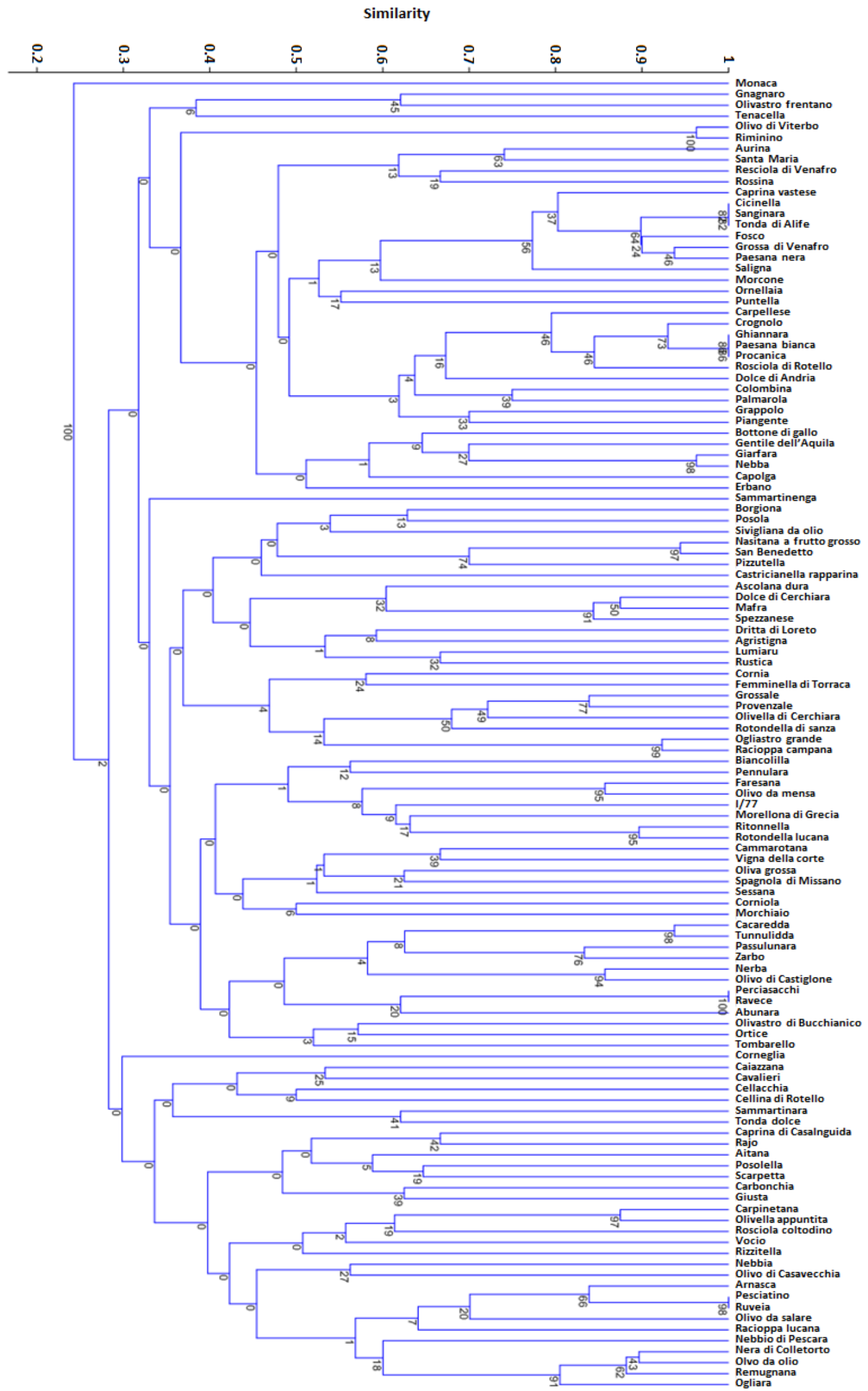

Figure 5. Dendrogram of relationships among the 120 olive varieties. 
Table 2. Parameters of genetic diversity for each SSR marker.

\begin{tabular}{ccccccccc}
\hline Locus & Na & Ho & He & HW & F (null) & PIC & NE-I & NE-SI \\
\hline dca3 & 11 & 0.916 & 0.847 & $*$ & -0.0421 & 0.824 & 0.044 & 0.339 \\
dca5 & 15 & 0.831 & 0.696 & $* * *$ & -0.1179 & 0.673 & 0.114 & 0.432 \\
dca8 & 18 & 0.975 & 0.845 & $* *$ & -0.0760 & 0.822 & 0.044 & 0.340 \\
dca16 & 23 & 0.689 & 0.858 & $* *$ & 0.1122 & 0.843 & 0.033 & 0.331 \\
dca18 & 12 & 0.957 & 0.852 & NS & -0.0607 & 0.831 & 0.041 & 0.336 \\
gapu71b & 8 & 0.881 & 0.784 & $* * *$ & -0.0626 & 0.745 & 0.084 & 0.381 \\
emo090 & 8 & 0.786 & 0.713 & NS & -0.0621 & 0.672 & 0.122 & 0.426 \\
dca9 & 22 & 0.924 & 0.898 & NS & -0.0182 & 0.884 & 0.021 & 0.308 \\
udo15 & 8 & 0.75 & 0.858 & ND & ND & 0.78 & 0.063 & 0.363 \\
udo12 & 3 & 0.733 & 0.66 & NS & -0.0842 & 0.565 & 0.204 & 0.482 \\
dca11 & 10 & 0.379 & 0.771 & $* * *$ & 0.3390 & 0.735 & 0.085 & 0.389 \\
olest23 & 3 & 0.4 & 0.511 & ND & ND & 0.41 & 0.341 & 0.605 \\
\hline Mean & 11.75 & 0.77 & 0.77 & & & 0.73 & & \\
\hline
\end{tabular}

Allele number $(\mathrm{Na})$; observed heterozygosis $(\mathrm{Ho})$; expected heterozygosis $(\mathrm{He})$; statistical significance of $\mathrm{HW}$ test *** $P<0.01, * P<0.05$; probability of null alleles (F); polymorphism information content (PIC); the non-exclusion probability between two unrelated individuals (NE-I); and two hypothetical full siblings (NE-SI).

The fixation indices Fis, Fit, and Fst showed a mean of $-0.14,0.01$, and 0.13 , respectively. The positive value of the Fst index seems to indicate a certain degree of differentiation between populations, as indicated by structure analysis results. The gene flow parameter $(\mathrm{Nm})$ was on average 1.64. indicating that a gene movement occurred among populations.

Allele frequencies varied from a minimum of 0.0042 to a maximum of 0.52 , with at least one rare allele for almost all the loci, aside from the locus UDO12. The most frequent allele was $206 \mathrm{bp}$ at the locus DCA5. Unique alleles found and the corresponding varieties are shown in Table 3.

Table 3. Rare alleles detected for each microsatellite locus in the 120 olive varieties.

\begin{tabular}{cccc}
\hline Cultivar & Provenience & Allele Size & Locus \\
\hline Carbonchia & Abruzzo & 159 & DCA18 \\
Rustica & Abruzzo & 202 & DCA9 \\
Sammartinenga & Basilicata & 241 & DCA3 \\
Sammartinenga & Basilicata & 164 & DCA16 \\
Scarpetta & Basilicata & 184 & EMO090 \\
Giusta & Basilicata & 196 & DCA5 \\
Corniola & Calabria & 135 & DCA8 \\
Dolce di Cerchiara & Calabria & 162 & DCA16 \\
Santa Maria & Campania & 255 & DCA3 \\
Corneglia & Campania & 204 & DCA5 \\
Olivone di Viterbo & Lazio & 136 & DCA16 \\
Gnagnaro & Molise & 134 & DCA16 \\
Rosciola di Rotello & Molise & 196 & EMO090 \\
Gnagnaro & Molise & 130 & DCA11 \\
Biancolilla & Sicilia & 210 & DCA9 \\
Bottone di Gallo & Sicilia & 129 & DCA8 \\
Castricianella Rapparina & Sicilia & 161 & DCA8 \\
Castricianella Rapparina & Sicilia & 192 & EMO090 \\
Erbano & Sicilia & 166 & DCA9 \\
Rajo & Umbria & 188 & DCA9
\end{tabular}

The dendrogram was divided in two main groups (Figure 5). The first one included the Monaca cultivar alone. The second one was divided into three subgroups with a large degree of genetic diversity. Considering a threshold of about 0.2-0.25, related to an allele difference of 1 or 2 alleles in 
genetic diversity [31,38], 16 putative synonymous groups (Table 4) were distinguished through cluster analysis, with a Dice similarity index ranging from 0.77 to 1 .

Table 4. List of the 17 synonymy groups found amongst the 120 olive varieties, their geographic origin, genetic similarity (Dice's index), and the corresponding group found with the population structure analysis.

\begin{tabular}{|c|c|c|c|}
\hline Cultivar & $\begin{array}{l}\text { Geographic } \\
\text { Provenience }\end{array}$ & Dice Similarity Index & Structure Group \\
\hline Carpinetana & Abruzzo & 0.87 & admixture \\
\hline Olivella Appuntita & Campania & & admixture \\
\hline Arnasca & Liguria & 0.84 & Red \\
\hline Pesciatino & Toscana & 1 & Red \\
\hline Ruveia & Campania & & Red \\
\hline Ogliara & Campania & $0.87 ; 0.77 ; 0.77$ & Red \\
\hline Olivo da olio & Campania & $0.9 ; 0.9$ & Red \\
\hline $\begin{array}{l}\text { Gentile Nera di } \\
\text { Colletorto }\end{array}$ & Molise & 0.87 & Red \\
\hline Remugnana & Molise & & Red \\
\hline Faresana & Basilicata & 0.86 & admixture \\
\hline Olivo da Mensa & Basilicata & & admixture \\
\hline Ritonnella & Campania & 0.9 & admixture \\
\hline Rotondella lucana & Basilicata & & admixture \\
\hline Dolce di Cerchiara & Calabria & $0.87 ; 0.81$ & Red \\
\hline Mafra & Calabria & 0.87 & Red \\
\hline Spezzanese & Calabria & & Red \\
\hline Nasitana Frutto Grosso & Sicilia & 0.94 & Red \\
\hline San Benedetto & Puglia & & Red \\
\hline Cacaredda & Sicilia & 0.94 & Red \\
\hline Tunnulidda & Sicilia & & Red \\
\hline Nerba & Sicilia & 0.86 & Red \\
\hline Olivo di Castiglione & Sicilia & & Red \\
\hline Perciasacchi & Campania & 1 & admixture \\
\hline Ravece & Campania & & admixture \\
\hline Grossale & Campania & 0.84 & Red \\
\hline Provenzale & Campania & & Red \\
\hline Ogliastro grande & Campania & 0.93 & Red \\
\hline Racioppa Campana & Campania & & Red \\
\hline Giarfara & Sicilia & 0.96 & Green \\
\hline Nebba & Sicilia & & Green \\
\hline Carpellese & Campania & $0.77 ; 0.84 ; 0.84 ; 0.81 ; 0.71$ & Green \\
\hline Crognolo & Lazio & $0.94 ; 0.93 ; 0.92 ; 0.8$ & Green \\
\hline Ghiannara & Basilicata & $1 ; 1 ; 0.87$ & Green \\
\hline Paesana Bianca & Molise & $1 ; 0.87$ & Green \\
\hline Procanica & Lazio & 0.85 & Green \\
\hline Rosciola di Rotello & Molise & & Green \\
\hline Caprina vastese & Abruzzo & $\begin{array}{c}0.83 ; 0.83 ; 0.83 ; 0.8 ; 0.76 ; \\
0.77\end{array}$ & Green \\
\hline Cicinella & Campania & $1 ; 1 ; 0.9 ; 0.93 ; 0.87$ & Green \\
\hline Sanginara & Campania & $1 ; 0.9 ; 0.93 ; 0.87$ & Green \\
\hline Tonda di Alife & Campania & $0.9 ; 0.93 ; 0.87$ & Green \\
\hline Fosco & Lazio & $0.9 ; 0.9$ & Green \\
\hline Grossa di Venafro & Molise & 0.94 & Green \\
\hline Paesana nera & Molise & & Green \\
\hline Olivone di Viterbo & Lazio & 0.96 & admixture \\
\hline Riminino & Lazio & & admixture \\
\hline Passulunara & Sicilia & 0.83 & Red \\
\hline Zarbo & Sicilia & & Red \\
\hline
\end{tabular}


For completeness of information, considering a wider dataset of over 300 Italian varieties whose genetic profile has been previously characterized in our laboratories [53], the cultivar Scarpetta (from Basilicata) showed the same molecular profile to Santagatese (from Sicily) likewise Carpellese (from Campania) to Correggiolo (from Emilia Romagna), Palmarola (from Basilicata) to Leccino (from Toscana), Fosco (from Lazio) to Moraiolo, Morinello (both from Tuscany) and Paesana nera (from Molise), and Paesana bianca (from Molise) to Frantoio (from Umbria).

The population structure analysis detected two main groups $(\mathrm{K}=2)$, termed "Red" and "Green", and a few admixed accessions. Overall, this is consistent with the cluster analysis. The "Red" group included most of the cultivars from Abruzzo, Basilicata, Campania, and Sicilia, as well as all of the olive cultivars from Calabria (Figure 6). With the exception of the Calabrian accessions, no clear geographic division was highlighted by the structure analysis. However, excluding rare alleles (allele frequency $0.042-0.084$ ), the following alleles were not found in the Green group, thus confirming a certain degree of genetic differentiation: 245bp (DCA3), $200 \mathrm{bp}, 210 \mathrm{bp}, 212 \mathrm{bp}, 214 \mathrm{bp}$ (DCA5), 127bp, 131bp, $145 \mathrm{bp}$, 157 bp (DCA8), 122bp, 154bp, 166bp, 168bp, 176bp, 178bp (DCA16), 171bp, 183bp (DCA18), 186bp, 192bp, 198bp (DCA9).
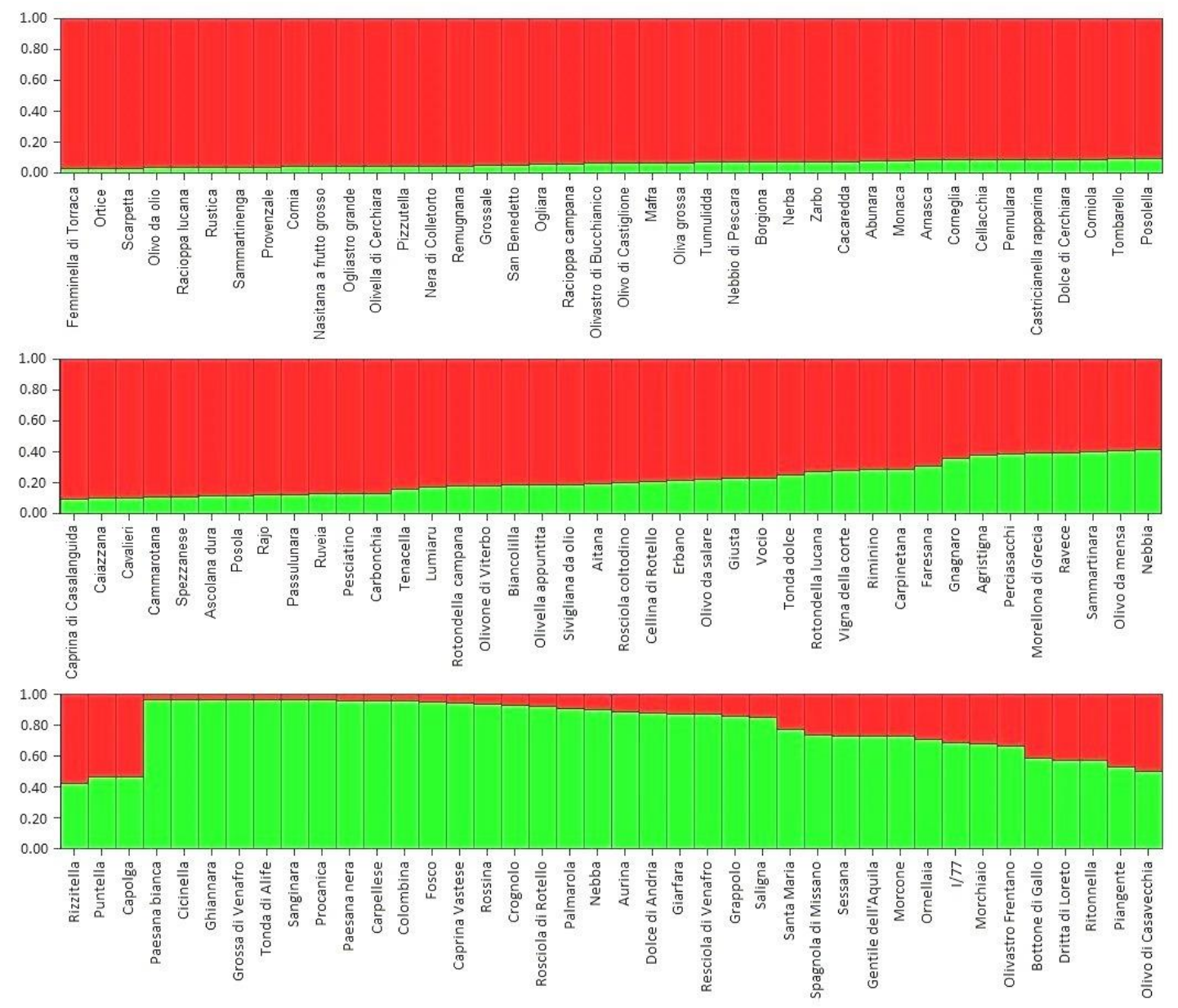

Figure 6. Population structure analysis showing the two differentiated groups (Red and Green) and the list of red, green, and admixed cultivars.

A correspondence of this genetic division into two major groups has been sought for the physiological characteristics through means of hierarchical clustering (Figure 7). Pearson's correlation coefficient was used to create a pairwise percentage similarity matrix and the dendrogram was derived using the unweighted pair group method with arithmetic averages (UPGMA). Although the distinction between these two groups was not so clear, a certain degree of separation could nonetheless be observed. 
Specifically, using a 0.8 similarity level, three clusters composed of six, 60, and 53 cultivars were highlighted, plus a single cultivar that did not cluster with others. The six-varieties group consisted only of "Red", which accounted for $70 \%$ in the 60 -cultivars group and $41 \%$ in the third cluster. This latter group contained the majority (68\%) of the "Green" varieties, accounting for $40 \%$ of the cluster, compared with $17 \%$ within the wider group.

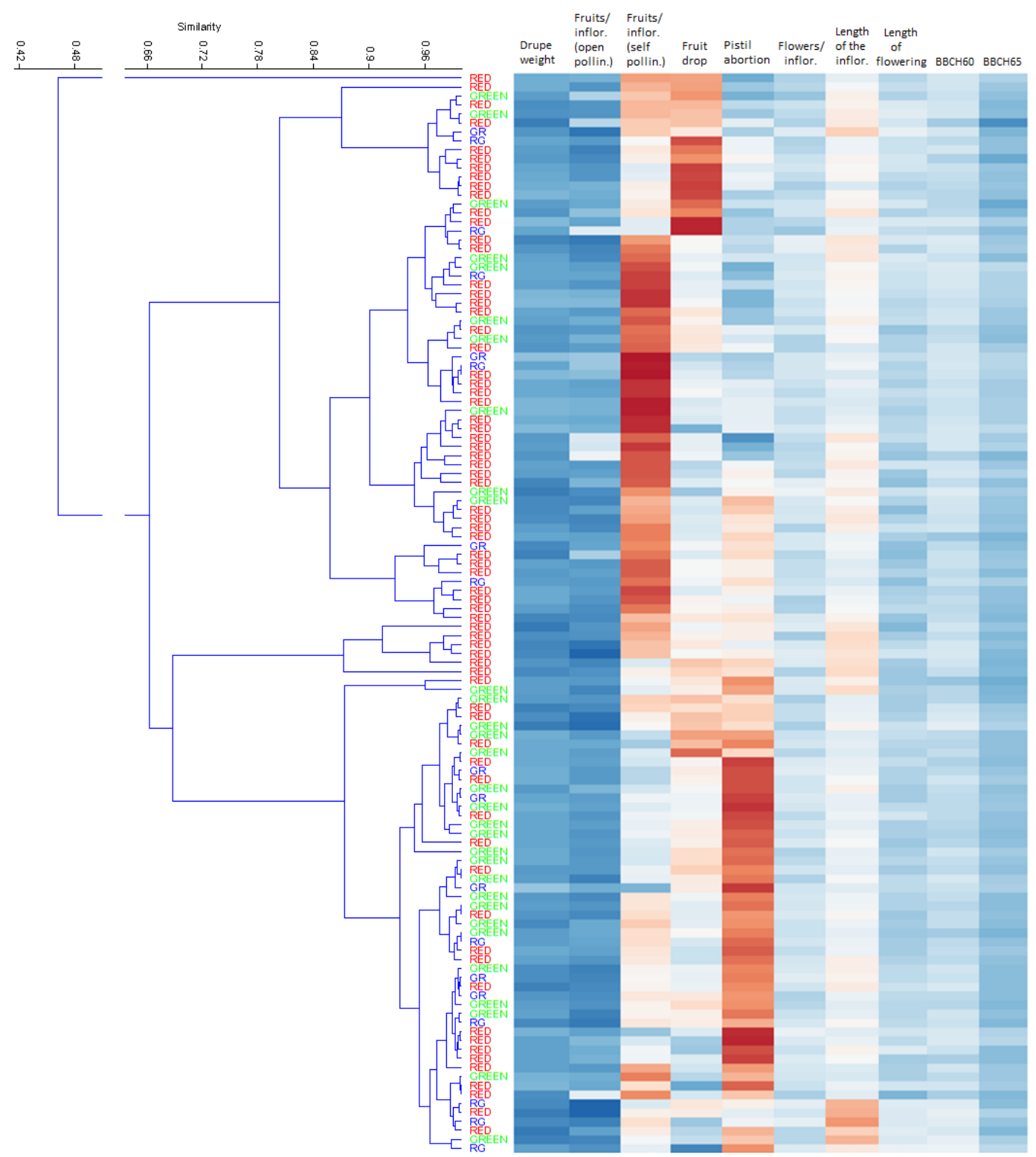

Figure 7. Hierarchical clustering of the principal phenological characters investigated in this work. Columns are clustered using correlation similarity and average linkage (UPGMA). GR -dominance of Green over Red- and RG -dominance of Red over Green-: admixed accessions.

The non-exclusion probability between two unrelated individuals (NE-I) and two hypothetical full siblings (sibling identity, NE-SI) ranged from 0.021 (DCA9) to 0.34 (OLEST23) and from 0.31 (DCA9) to 0.6 (OLEST23), respectively. Parentage analysis revealed critical LOD scores of 18.99 and 16.43 for the parent pair analysis, with unknown sexes for strict $(99 \%)$ and relaxed $(95 \%)$ confidence levels. The main putative pairs of parents, with a maximum of one mismatch for each one, are shown in Table 5 . The putative parents of 21 cultivars were assigned. In the case of seven cultivars, the offspring and one 
of the two parents shared the same region of origin, whilst in only one case did the two parents belong to confining regions.

Table 5. Parentage analysis results. The table shows the olive cultivars identified as putative parents of the offspring cultivars, and the corresponding regions of origin.

\begin{tabular}{|c|c|c|c|c|c|}
\hline Offspring ID & Region & $\begin{array}{c}\text { First } \\
\text { Candidate ID }\end{array}$ & Region & $\begin{array}{c}\text { Second } \\
\text { Candidate ID }\end{array}$ & Region \\
\hline Abunara & Sicily & Giarfara & Sicily & Scarpetta & Basilicata \\
\hline Aitana & Sicily & Giarfara & Sicily & Scarpetta & Basilicata \\
\hline Capolga & Marche & $\begin{array}{l}\text { Morellona di } \\
\text { Grecia }\end{array}$ & Puglia & Rossina & E. Romagna \\
\hline Colombina & E. Romagna & Carpellese & Campania & Palmarola & Basilicata \\
\hline $\begin{array}{c}\text { Gentile } \\
\text { dell'Aquila }\end{array}$ & Abruzzo & Fosco & Lazio & Posola & Abruzzo \\
\hline Grappolo & Tuscany & Paesana Bianca & Molise & Piangente & Tuscany \\
\hline $\mathrm{I} / 77$ & Umbria & Cicinella & Campania & $\begin{array}{c}\text { Olivo di } \\
\text { Castiglione }\end{array}$ & Sicily \\
\hline Lumiaru & Sicily & Caiazzana & Campania & Rustica & Abruzzo \\
\hline Oliva grossa & E. Romagna & $\begin{array}{l}\text { Spagnola di } \\
\text { Missano }\end{array}$ & Liguria & Zarbo & Sicily \\
\hline Olivo da salare & Campania & Arnasca & Liguria & Bottone di gallo & Sicily \\
\hline Palmarola & Basilicata & Colombina & E. Romagna & Paesana bianca & Molise \\
\hline Rizzitella & Campania & Bottone di gall & Sicily & $\begin{array}{c}\text { Racioppa } \\
\text { lucana }\end{array}$ & Basilicata \\
\hline $\begin{array}{l}\text { Rosciola } \\
\text { coltodino }\end{array}$ & Lazio & Carpinetana & Abruzzo & $\begin{array}{c}\text { Racioppa } \\
\text { lucana }\end{array}$ & Basilicata \\
\hline Rossina & E. Romagna & Giarfara & Sicily & Paesana near & Molise \\
\hline Sammartinara & Sicily & Nebba & Sicily & Scarpetta & Basilicata \\
\hline Santa Maria & Campania & Aurina & Molise & Rossina & E. Romagna \\
\hline Sessana & Campania & Procanica & Lazio & $\begin{array}{c}\text { Vigna della } \\
\text { Corte }\end{array}$ & Campania \\
\hline $\begin{array}{l}\text { Spagnola di } \\
\text { Missano }\end{array}$ & Liguria & Carpellese & Campania & Oliva grossa & E. Romagna \\
\hline Vigna della corte & Campania & Monaca & Sicily & $\begin{array}{c}\text { Rotondella } \\
\text { lucana }\end{array}$ & Basilicata \\
\hline Vocio & Umbria & Carpinetana & Abruzzo & Olivo da salare & Campania \\
\hline Zarbo & Sicily & Giarfara & Sicily & Scarpetta & Basilicata \\
\hline & \multicolumn{5}{|c|}{$\begin{array}{l}\text { One of the parental genotypes and the offspring share the same region of origin. } \\
\text { Neighboring regions of origin for the two parental genotypes. } \\
\text { No type of geographical relationship. }\end{array}$} \\
\hline
\end{tabular}

Of note is the finding that three Sicilian cultivars, Aitana, Abunara, and Zarbo, are very likely siblings; their putative parents were Giarfara and Scarpetta from Sicily and Basilicata, respectively.

\section{Discussions}

\subsection{Bio-Agronomic Characterization}

An overall examination of all the reported data highlights that almost all of the analyzed parameters showed considerable variability, which given environmental and crop-management uniformity, is indicative of a large genetic variability in the accessions under observation.

All of the examined varieties, with one single exception (Pennulara), showed low percentages of self-fruit-set, indicating the need for the employment of suitable pollinator plants, whereas the 
flowering time amongst the different cultivars in the same environment was found to vary from three to four weeks (flowering scalarity).

On average, the fruit set per flowering bud was of an order 10 times greater than that per fertile flower, be they open-pollinated or self-pollinated, whilst the fruit set by open pollination was approximately 13 times greater than that from self-pollination. This confirms, from an agronomic point of view, the need for the presence of pollinators, and particularly the need for the selection of suitable pollinators, whereas some cultivars are genetically or physiologically (e.g., asynchronous flowering phases) inter-incompatible [54,55]. For this reason, it must be considered that in our trial, open pollination was favored by the presence of hundreds of different cultivars compared to a typical olive grove. Moreover, even in self-compatible varieties, open pollination might be nonetheless advantaged by the fact that ovary receptivity begins even before the opening of the flower, lasting for five to seven days, whilst the maximum emission of pollen occurs three or four days after the opening of the flowers [56].

The data on the fruit set calculated per fertile flower highlighted that regardless of the imponderable likelihood of pollen grains settling on the fertile flower during receptivity, the aspects linked to cytological and factorial sterility—already described for olive trees [57]—quite significantly affect the chances of fertilization of the ovule, and consequently (together with the aforementioned morphological sterility), the plants' productive potential. Indeed, in addition to cases of infertility due to climatic reasons (environmental sterility) or erroneous cultivation techniques, there are those cases that are due to genetics-morphological, cytological, and factorial sterility. Morphological sterility manifests itself in both partial and total pistil abortions (gyno-sterility), and in either absent or deficient stamen and pollen development (andro-sterility). Cytological sterility depends on disturbances in meiosis during the sporogenesis processes for irregular matching of chromosomes. The flowers are morphologically normal, but the anther emits little pollen, which is not very germinable or sterile. In the case of factorial sterility, the pollen, whilst being vital and germinable, is incapable of fertilizing the flowers of the same cultivar (self-incompatibility) or of any other non-similar cultivar (inter-incompatibility).

With regards to the correlation between the number of flowers per inflorescence and pistil abortion, a positive and statistically significant correlation of $99 \%$ was found (Figure 8). This correlation is even more striking for the extreme values of the two parameters. Indeed, in the nine cultivars with flowering buds bearing an average of 24 flowers, the percentage of pistil abortion ended up being equal to $67.57 \%$, whilst in the 10 varieties with fewer than 13 flowers per inflorescence, the average abortion percentage turned out to be barely $22.78 \%$. On the other hand, in the 11 varieties with over $75 \%$ abortion percentage, the average number of flowers per inflorescence was equal to 23.03, whilst in the 12 varieties with pistil abortions under $10 \%$ the average number of flowers per inflorescence was 15.21. This is in contrast to what has been previously suggested by Reale et al. [58]. Eventually, drupe weight statistically significantly negatively correlated with fruit set in open pollination and time of flowering, whilst positively correlating with fruit drop and the duration of flowering. Therefore, varieties with small drupes will generally produce more fruits that will be less prone to drop.

Fitting the GDD model on the whole dataset allowed us to rank cultivars according to the thermal requirement required to reach full flowering. Overall, the GDD requirement ranged between 1090 and $1380{ }^{\circ} \mathrm{C}$ per day, but it is to be noted that two-thirds of the cultivars under study $(67.5 \%)$ exhibited a much narrower variation, between 1292 and $1330{ }^{\circ} \mathrm{C}$ per day (Figure 4). As a consequence of this, most flowerings are highly concentrated over time, which could have further contributed to the high level of open pollination mentioned above, beyond the high cultivar concentration in the same grove.

Another aspect to be evidenced is that fitting the GDD model converged to base temperatures between $1{ }^{\circ} \mathrm{C}$ and $4.5^{\circ} \mathrm{C}$ (not shown), with $2.25^{\circ} \mathrm{C}$ as the average. In general, higher temperatures are reported, varying from $6^{\circ} \mathrm{C}$ to $12.5^{\circ} \mathrm{C}[49,59]$.

Calculation of base temperature may give varying results depending on the calculation methodology, and currently there is no agreement as to the best values to use [60-62]. 
Duration of flowering, expressed in thermal time, was also found to be cultivar specific, with no apparent correlation with earliness, unlike what was found when the period was expressed in calendar days. A likely explanation of this latter effect is that when flowering starts early it takes longer to complete because air temperature is colder, while late flowerings occur in a warmer period, which makes them shorter.

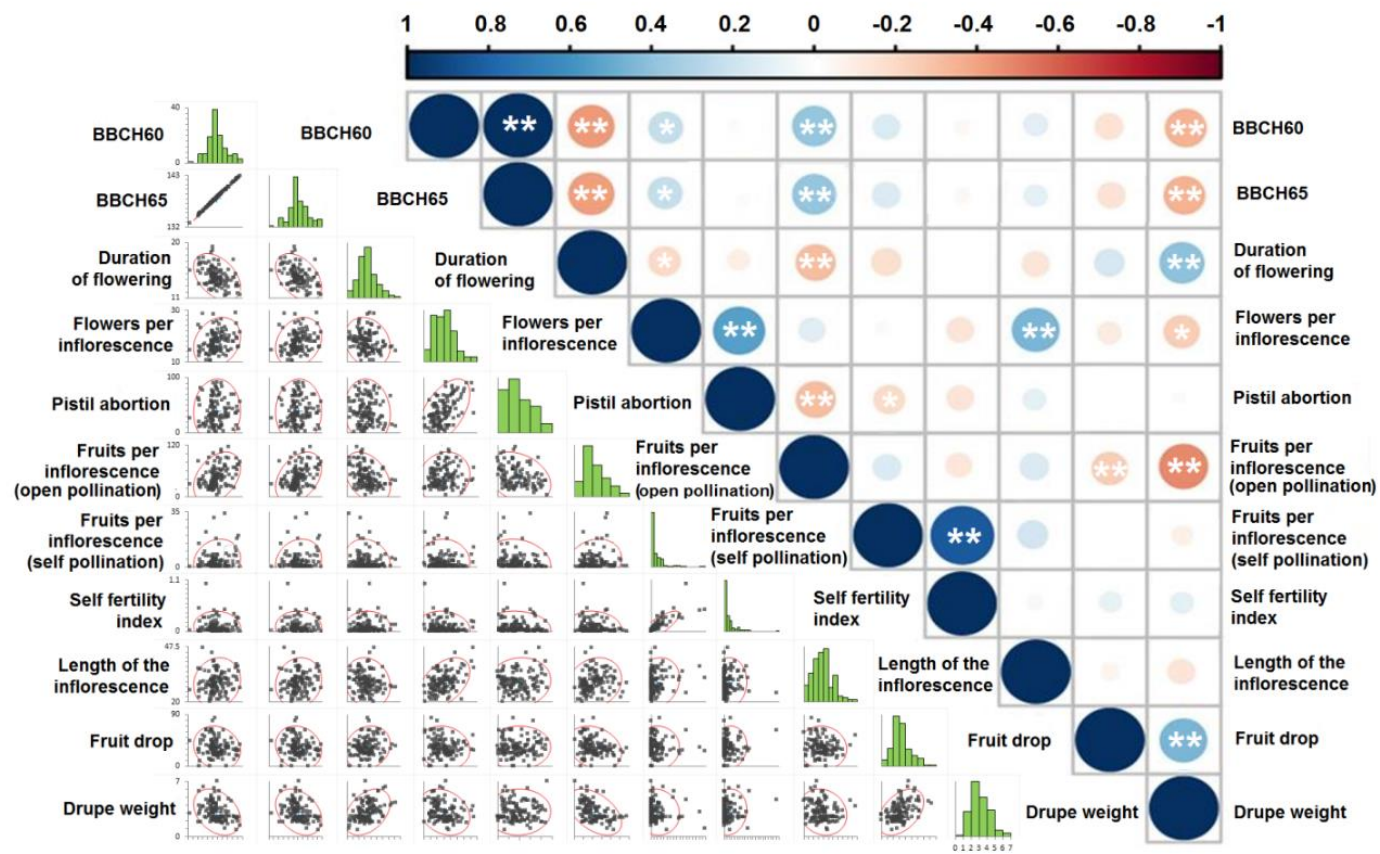

Figure 8. Correlation matrix based on Pearson's product-moment correlation coefficient (r) between paired variables, across the eight-year trial. Asterisks denote statistical significance at $95 \%\left({ }^{*}\right)$ and $99 \%$ $\left.{ }^{* *}\right)$ confidence levels.

\subsection{Molecular Characterisation}

The analysis of the genetic variability and population structure confirmed a high genetic variability and low degree of differentiation (only two groups), with no clear geographic division, apart from the Calabrian varieties. Our results only partially overlap with those of Muzzalupo et al. [31]. This work analyzed a larger set of cultivars (439 Italian varieties) from the same collection, identifying 7 genetic clusters. Main and minor olive varieties were also evaluated by Marra et al. [63] from three distinct regions (Calabria, Sicily, and Campania), indicating more shared allele profiles, especially between Campanian and Calabrian olive germplasm. Discrepancies in olive germplasm genetic analysis results are often due to methodological approaches, such as different sets of SSR markers, no reference authenticated cultivars analyzed, and different instruments used, especially genetic analyzers, leading to great confusion in terms of knowledge about the genetic characterization in olive [30]. Our results tend to align more closely with those of Marra et al. [63], also considering the same methodology and the greater number of common markers used. The parentage analysis seems to confirm the genetic analysis of population structure. Except for Sicily region, where a certain number of geographic barriers can be found justifying cross-pollination among local varieties, in the other cases, the different geographic origins of the putative parentals clearly indicate that gene flow occurred, reducing the genetic differentiation. The "movement" of the olive varieties throughout the Italian peninsula is further confirmed by the presence of several cases of synonymy (seven groups, Table 4) found amongst plants cultivated in different regions.

Some of the synonymies recorded in this work have previously been partially described [31,53], although the following 10 groups of synonymies are being reported for the first time: (1) Carpinetana/Olivella appuntita; (2) Passulunara/Zarbo; (3) Ritonnella/Rotondella lucana; (4) Nasitana 
a frutto grosso/San Benedetto; (5) Perciasacchi/Ravece; (6) Ogliastro grande/Racioppa campana; (7) Giarfara/Nebba; (8)Carpellese/Frantoio; (9) Dolce di Cerchiara as a synonym of Mafra and Spezzanese; and (10) Arnasca as a synonym of Pesciatino and Ruveia.

Eventually, the normally distributed physiological variables of the varieties found to be synonyms were subjected to a principal component analysis (Figure 9) to evaluate the correspondence with the molecular analyses. Generally, the close clustering of the synonymy groups confirmed microsatellite markers as a reliable system for the discrimination of the olive varieties, whereas the substantial differences found amongst some of the putative synonymous varieties could be due to the comparison between local ecotypes that may have developed phenological, physiological, and structural adaptations to their original environmental conditions.

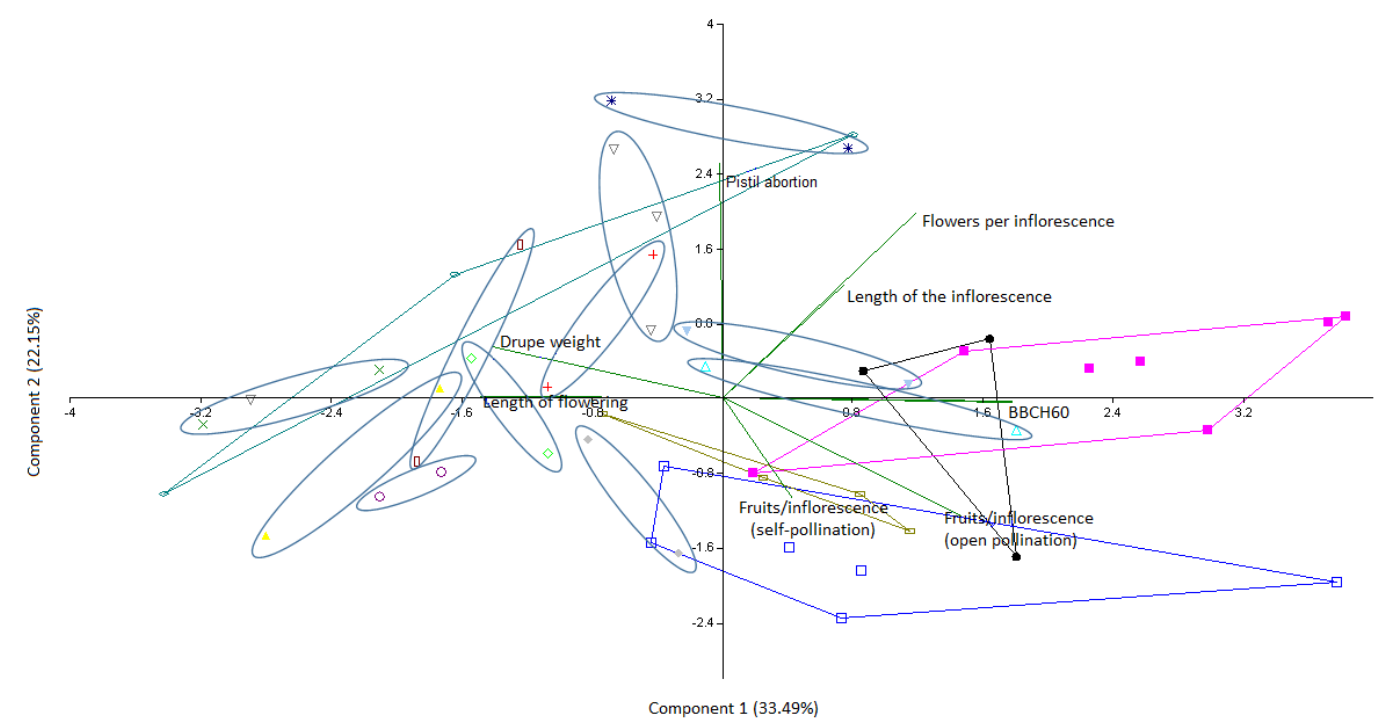

Figure 9. Principal component analysis of the normally distributed physiological parameters obtained from the molecularly revealed cases of synonymy.

\section{Conclusions}

This work provides an important contribution to the characterization of the Italian olive biodiversity through the study, at both molecular and physiological levels, of 120 varieties that have traditionally been marginalized. The bio-agronomic characterization provides a basic understanding of the varieties of olive, which is indispensable for not only proper classification, but also for the design and development of future studies that, given the incredibly rich germplasm, are definitely needed in order to increase knowledge about this valuable species. For instance, the identification of a self-fertile cultivar represents a notable datum within what is generally considered a self-sterile species. Furthermore, a greater knowledge of the floral and fruiting biology might allow for the rediscovery and revaluation of many of these varieties, for the purpose of eventually reintroducing them into their areas of origin (or taken beyond to other areas), or for utilization in future breeding programs. In the same regard, the proper varietal identification using molecular markers is an extremely important requirement for the use and marketing of propagation material of agricultural plants. Finally, the observations, based on a large number of varieties and repeated over an eight-year period, aside from providing interesting information on individual cultivars, have allowed us to draw up general rules on the floral biology of the olive tree. 
Supplementary Materials: The following are available online at http://www.mdpi.com/2079-7737/8/3/62/s1, Table S1: Models for predicting flowering date which were tested, Table S2: Results of the cross validation test for all the models under study, Table S3: Specific cumulated heat requirement for each cultivar under study, calculated by fitting SW1 model (Table S1) to data.

Author Contributions: Data curation, L.L., G.F., N.L., C.E., D.H.D.III, A.S. and S.Z.; Formal analysis, L.L., G.F., N.L., C.E., G.G., A.S. and S.Z.; Investigation, L.L., N.L.,G.G. and S.Z.; Methodology, L.L., G.F., N.L. and S.Z.; Software, L.L., A.S. and S.Z.; Supervision, N.L.; Writing-original draft, L.L., G.F., A.S. and S.Z.; Writing一review \& editing, L.L. and D.H.D.III.

Funding: This research received no external funding.

Acknowledgments: We thank Agraria Riva del Garda s.c.a. for the economic support.

Conflicts of Interest: The authors declare no conflict of interest.

\section{References}

1. Aguilera, F.; Valenzuela, L.R. Microclimatic-induced fluctuations in the flower and pollen production rate of olive trees (Olea europaea L.). Grana 2012, 51, 228-239. [CrossRef]

2. Lavee, S.; Rallo, L.; Rapoport, H.F.; Troncoso, A. The floral biology of the olive, effect of flower number, type and distribution on fruitset. Sci. Hortic. 1996, 66, 149-158. [CrossRef]

3. Cuevas, J.; Polito, V.S. The role of staminate flowers in the breeding system of Olea europaea (Oleaceae), an andromonoecious, wind-pollinated taxon. Ann. Bot. 2004, 93, 547-553. [CrossRef] [PubMed]

4. Camposeo, S.; Ferrara, G.; Palasciano, M.; Godini, A. About the biological behaviour of cv. Coratina. Acta Hortic. 2012, 949, 129-133. [CrossRef]

5. Farinelli, D.; Boco, M.; Tombesi, A. Results of four years of observations on self-sterility behaviour of several olive cultivars and significance of cross-pollination. In Proceedings of the 2nd International Seminar Olivebioteq, Marsala-Mazara del Vallo, Italy, 5-10 November 2006; Volume 1, pp. 275-282.

6. Rojo, J.; Salido, P.; Pérez-Badia, R. Flower and pollen production in the 'Cornicabra' olive (Olea europaea L.) cultivar and the influence of environmental factors. Trees 2015, 29, 1235-1245. [CrossRef]

7. FAO. The Second Report on the State of the World's Plant Genetic Resources for Food and Agriculture; FAO: Rome, Italy, 2010; 370p, ISBN 978-92-5-106534-1.

8. Petri, L. Osservazioni sulla biologia e patologia del fiore dell'olivo. Atti Reale Accad. Lincei 1910, $19,436-454$.

9. Campbell, C. L'aborto Fiorale dell' Olivo; Italia Agricola: Massanzago, Italy, 1911.

10. Bradley, M.V.; Griggs, W.H. Morphological evidence of incompatibility in Olea europaea L. Phytomorphology 1963, 13, 141-156.

11. Villemur, P.; Musho, U.S.; Delmas, J.M.; Maamar, M.; Ouksili, A. Contribution à l'étude de la biologie florale de l'olivier (Olea europaea L.), stérilité mâle, flux pollinique et période effective de pollinisation. Fruits 1984, 39, 467-473.

12. Mookerjee, S.; Guerin, J.; Collins, G.; Ford, C.M. Paternity analysis using microsatellite markers to identify pollen donors in an olive grove. Theor. Appl. Genet. 2005, 111, 1174-1182. [CrossRef]

13. Moutier, N.; Terrien, E.; Pécout, R.; Hostalnou, E.; Margier, J.F. Un groupe d'étude des compatibilités polliniques entre variétés d'olivier. Nouv. Oliv. 2006, 51, 8-11.

14. Diaz, A.; Martin, A.; Rallo, P.; Barranco, D.; De la Rosa, R. Self-incompatibility of 'Arbequina' and 'Picual' olive assessed by SSR Markers. JASHS 2006, 131, 250-255. [CrossRef]

15. El-Hady, E.S.; Haggag, L.F.; Abdel-Migeed, M.M.M.; Desouky, I.M. Studies on sex compatibility of some olive varieties. Res. J. Agric. Biol. Sci. 2007, 3, 504-509.

16. Farinelli, D.; Hassani, D.; Tombesi, A. Self-sterility and cross-pollination responses of nine olive cultivars in Central Italy. In Proceedings of the Fifth Symposium on Olive Growing, Izmir, Turkey, 27 September-3 October 2004.

17. Taslimpour, M.; Bonyampour, A.; Rahemi, R. Determining the best pollinizer of olive (Olea europaea L.) (Dezfoul') in Fars Province. Am. Euras. J. Agric. Environ. Sci. 2008, 4, 682-686.

18. Eassa, K.B.; El-Tweel, A.A.; Gorda, A.M. Studies and cross-pollination for Kalamata olive cultivar grown on a sandy soil. J. Agric. Kafer El-Sheik Univ. 2011, 37, 127-140. 
19. Rosati, A.; Caporali, S.; Paoletti, A.; Famiani, F. Pistil abortion is related to ovary mass in olive (Olea europaea L.). Sci. Hortic. 2011, 127, 515-519. [CrossRef]

20. Sadok, I.B.; Celton, J.M.; Essalouh, L.; El Aabidine, A.Z.; Garcia, G.; Martinez, S.; Grati-Kamoun, N.; Rebai, A.; Costes, E.; Bouchaib Khadari, B. QTL Mapping of Flowering and Fruiting Traits in Olive. PLoS ONE 2014, 9 , e62831. [CrossRef]

21. Rallo, L.; Barranco, D.; Díez, C.M.; Rallo, P.; Paz Suárez, M.; Trapero, C.; Pliego-Alfaro, F. Strategies for Olive (Olea europaea L.) Breeding: Cultivated Genetic Resources and Crossbreeding. In Advances in Plant Breeding Strategies: Fruits; Al-Khayri, J., Jain, S., Johnson, D., Eds.; Springer: Cham, Switzerland, 2018.

22. Bartolini, S.; Guerriero, R. Self-compatibility in several clones of oil olive cv. Leccino. Adv. Hortic. Sci. 1995, 9, 71-74.

23. Lombardo, N.; Alessandrino, M.; Godino, G.; Madeo, A. Comparative observation regarding the floral biology of 150 Italian olive (Olea europaea L.) cultivars. Adv. Hortic. Sci. 2006, 4, 247-255.

24. Lombardo, L.; Lombardo, N.; Briccoli Bati, C. Osservazioni sulla biologia fiorale e di fruttificazione dell'olivo. Acta Italus Hortus 2011, 1, 194-197.

25. Santilli, E.; Lombardo, L.; Varlaro, M.; Nannelli, R.; Gagnarli, E.; Briccoli Bati, C. Effectiveness of the GAEC cross compliance standard Maintenance of olive groves in good vegetative condition in avoiding the deterioration of habitats and land abandonment. Ital. J. Agron. 2011, 6, e15. [CrossRef]

26. Mariotti, R.; Mousavi, S.; Pandolfi, S.; Cultrera, N.G.M.; Costantini, L.; Baldoni, L. La Coltivazione Antica Dell'olivo a Confronto con le Varietà Attuali: Il Contributo Della Ricerca Genetica; Rivista di Storia dell'Agricoltura: Firenze, Italy, 2016; pp. 1-2.

27. Bartolini, G. Olive Germplasm (Olea europaea L.), Cultivars, Synonyms, Cultivation Area, Collections, Descriptors. Available online: http://www.oleadb.it/ (accessed on 24 June 2019).

28. D’Agostino, N.; Taranto, F.; Camposeo, S.; Mangini, G.; Fanelli, V.; Gadaleta, S.; Miazzi, M.M.; Pavan, S.; Di Rienzo, V.; Sabetta, W.; et al. GBS-derived SNP catalogue unveiled wide genetic variability and geographical relationships of Italian olive cultivars. Sci. Rep. 2018, 8, 15877. [CrossRef] [PubMed]

29. Sanz-Cortes, F.; Martinez-Calvo, J.; Badenes, M.L.; Bleiholder, H.; Hack, H.; Llacer, G.; Meier, U. Phenological growth stages of olive trees (Olea europaea). Ann. Appl. Biol. 2002, 140, 151-157. [CrossRef]

30. Baldoni, L.; Cultrera, N.G.; Mariotti, R.; Ricciolini, C.; Arcioni, S.; Vendramin, G.G.; Buonamici, A.; Porceddu, A.; Sarri, V.; Ojeda, M.A.; et al. A consensus list of microsatellite markers for olive genotyping. Mol. Breed. 2009, 24, 213-231. [CrossRef]

31. Muzzalupo, I.; Vendramin, G.G.; Chiappetta, A. Genetic Biodiversity of Italian Olives (Olea europaea) Germplasm Analyzed by SSR Markers. Sci. World J. 2014, 2014, 296590. [CrossRef] [PubMed]

32. Sarri, V.; Baldoni, L.; Porceddu, A.; Cultrera, N.; Contento, A.; Frediani, M.; Belaj, A.; Trujillo, I.; Cionini, P. Microsatellite markers are powerful tools for discriminating among olive cultivars and assigning them to geographically defined populations. Genome 2006, 49, 1606-1615. [CrossRef] [PubMed]

33. Mohamed, M.B.; Zelasco, S.; Guasmi, S.B.; Triki, T.; Conforti, F.L.; Naziha, G.K. Exploring olive trees genetic variability in the South East of Tunisia. Genet. Mol. Res. 2017, 16, gmr16039850. [CrossRef]

34. Koehmstedt, A.M.; Aradhya, M.K.; Soleri, D.; Smith, J.L.; Polito, V.S. Molecular characterization of genetic diversity, structure, and differentiation in the olive (Olea europaea L.) germplasm collection of the United States Department of Agriculture. Genet. Res. Crop. Evol. 2011, 58, 519-531. [CrossRef]

35. Trujillo, I.; Ojeda, M.A.; Urdiroz, N.M.; Potter, D.; Barranco, D.; Rallo, L.; Diez, C.M. Identification of the Worldwide Olive Germplasm Bank of Córdoba (Spain)using SSR and morphological markers. Tree Genet. Genomes 2014, 10, 141-155. [CrossRef]

36. Sefc, K.M.; Lopes, M.S.; Mendonça, D.; Santos, M.R.D.; Machado, L.M.; Machado, A.D.C. Identification of microsatellite loci in olive (Olea europaea) and their characterization in Italian and Iberian olive trees. Mol. Ecol. 2000, 9, 1171-1173. [CrossRef]

37. Carriero, F.; Fontanazza, G.; Cellini, F.; Giorio, G. Identification of simple sequence repeats (SSRs) in olive (Olea europaea L.). Theor. Appl. Genet. 2002, 104, 301-307. [CrossRef]

38. Cipriani, G.; Marrazzo, M.T.; Marconi, R.; Cimato, A.; Testolin, R. Microsatellite markers isolated in olive (Olea europaea L.) are suitable for individual fingerprinting and reveal polymorphism within ancient cultivars. Theor. Appl. Genet. 2002, 104, 223-228. [CrossRef] [PubMed] 
39. De La Rosa, R.; James, C.M.; Tobutt, K.R. Isolation and characterization of polymorphic microsatellites in olive (Olea europaea L.) and their transferability to other genera in the Oleaceae. Mol. Ecol. Notes 2002, 2, 265-267. [CrossRef]

40. Mariotti, R.; Cultrera, N.G.M.; Mousavi, S.; Baglivo, F.; Rossi, M.; Albertini, E.; Alagna, F.; Carbone, F.; Perrotta, G.; Baldoni, L. Development, evaluation, and validation of new EST-SSR markers in olive (Olea europaea L.). Tree Genet. Genomes 2016, 12, 120. [CrossRef]

41. Dice, L.R. Measures of the Amount of Ecologic Association Between Species. Ecology 1945, 26, $297-302$. [CrossRef]

42. Sneath, P.H.; Sokal, R.R. Numerical Taxonomy the Principles and Practice of Numerical Classification, 1st ed.; W.H. Freeman and Co.: San Francisco, CA, USA, 1973; 573p.

43. Marshall, T.C.; Slate, J.; Kruuk, L.E.; Pemberton, J.M. Statistical confidence for likelihood-based paternity inference in natural populations. Mol. Ecol. 1998, 7, 639-655. [CrossRef] [PubMed]

44. Kalinowski, S.T.; Taper, M.L.; Marshall, T.C. Revising how the computer program CERVUS accommodates genotyping error increases success in paternity assignment. Mol. Ecol. 2007, 16, 1099-1106. [CrossRef]

45. Kalinowski, S.T.; Taper, M.L.; Marshallm, T.C. Corrigendum. Mol. Ecol. 2010, 19, 1512. [CrossRef]

46. Yeh, F.C.; Yang, R.C.; Boyle, T.B.; Ye, Z.; Mao, J.X. Popgene, the User-Friendly Shareware for Population Genetic Analysis; Molecular Biology and Biotechnology Centre, University of Alberta: Edmonton, AB, Canada, 1997; 10p.

47. Pritchard, J.K.; Stephens, M.; Donnelly, P.J. Inference of population Structure using multilocus genotype data. Genetics 2000, 155, 945-959.

48. Earl, D.A.; Von Holdt, B.M. Structure Harvester, a website and program for visualizing STRUCTURE output and implementing the Evanno method. Cons. Genet. Resour. 2012, 4, 359-361. [CrossRef]

49. Orlandi, F.; Lanari, D.; Romano, B.; Fornaciari, M. New model to predict the timing of olive (Olea europaea) flowering, a case study in central Italy. N. Z. J. Crop Hortic. Sci. 2006, 34, 93-99. [CrossRef]

50. Bonofiglio, T.; Orlandi, F.; Sgromo, C.; Romano, B.; Fornaciari, M. Influence of temperature and rainfall on timing of olive (Olea europaea) flowering in southern Italy. N. Z. J. Crop Hortic. Sci. 2008, 36, 59-69. [CrossRef]

51. Orlandi, F.; Avolio, E.; Bonofiglio, T.; Federico, S.; Romano, B.; Fornaciari, M. Potential shifts in olive flowering according to climate variations in Southern Italy. Meteorol. Appl. 2013, 20, 497-503. [CrossRef]

52. Burnham, K.P.; Anderson, D.R. Model Selection and Multimodel Inference, A Practical Information-Theoretic Approach, 2nd ed.; Springer-Verlag: New York, NY, USA, 2002; 488p.

53. Perri, E.; Zelasco, S.; Benincasa, C.; Vizzarri, V.; Carbone, F.; Lo Feudo, G.; Alessandrino, S.; Salimonti, A.; Romano, E.; Pellegrino, M.; et al. Il Germoplasma Olivicolo del Campo Collezione del Consiglio per la Ricerca in Agricoltura e l'analisi Dell'economia Agraria; Crea-oli Cosenza: Rende, Italy, 2016; 404p.

54. Marchese, A.; Marra, F.P.; Costa, F.; Quartararo, A.; Fretto, S.; Caruso, T. An investigation of the self- and inter-incompatibility of the olive cultivars 'Arbequina' and 'Koroneiki' in the Mediterranean climate of Sicily. Aust. J. Crop Sci. 2016, 10, 88-93.

55. Saumitou-Laprade, P.; Vernet, P.; Vekemans, X.; Billiard, S.; Gallina, S.; Essalouh, L.; Mhaïs, A.; Moukhli, A.; El Bakkali, A.; Barcaccia, G.; et al. Elucidation of the genetic architecture of self-incompatibility in olive, Evolutionary consequences and perspectives for orchard management. Evol. Appl. 2017, 10, 867-880. [CrossRef] [PubMed]

56. Serrano, I.; Olmedilla, A. Histochemical location of key enzyme activities involved in receptivity and self-incompatibility in the olive tree (Olea europaea L.). Plant Sci. 2012, 197, 40-49. [CrossRef] [PubMed]

57. Baldini, E. Aspetti genetici della sterilità dell'olivo. Olivicoltura 1951, 1, 3-9.

58. Reale, L.; Sgromo, C.; Bonofiglio, T.; Orlandi, F.; Fornaciari, M.; Ferranti, F.; Romano, B. Reproductive biology of Olive (Olea europaea L.) DOP Umbria cultivars. Sex. Plant Reprod. 2006, 19, 151-161. [CrossRef]

59. Galán, C.; Garcia-Mozo, H.; Vazquez, L.; Ruiz-Valenzuela, L.; Díaz de la Guardia, C.; Trigo-Perez, M. Heat requirement for the onset of the Olea europaea L. pollen season in several places of Andalusia region and the effect of the expected future climate change. Int. J. Biometeorol. 2005, 49, 184-188. [CrossRef]

60. Snyder, R.; Spano, D.; Cesaraccio, C.; Duce, P. Determining degree-day thresholds from field observations. Int. J. Biometeorol. 1999, 42, 177-182. [CrossRef]

61. Yang, S.; Logan, J.; Coffey, D.L. Mathematical formulae for calculating the base temperature for growing degree days. Agric. For. Meteorol. 1995, 75, 61-74. [CrossRef] 
62. Ruml, M.; Vuković, A.; Milatović, D. Evaluation of different methods for determining growing degree-day thresholds in apricot cultivars. Int. J. Biometeorol. 2010, 54, 411-422. [CrossRef] [PubMed]

63. Marra, F.P.; Caruso, T.; Costa, F.; Di Vaio, C.; Mafrica, R.; Marchese, A. Genetic relationships, structure and parentage simulation among the olive tree (Olea europaea L. subsp. europaea) cultivated in Southern Italy revealed by SSR markers. Tree Genet. Genomes 2013, 9, 961-973. [CrossRef]

(C) 2019 by the authors. Licensee MDPI, Basel, Switzerland. This article is an open access article distributed under the terms and conditions of the Creative Commons Attribution (CC BY) license (http://creativecommons.org/licenses/by/4.0/). 